\title{
Plasma Quench Production of Titanium from Titanium Tetrachloride
}

J. W. Sears

Published October 1994

Idaho National Engineering Laboratory Lockheed Idaho Technologies Company Idaho Falls, Idaho 83415
홍.

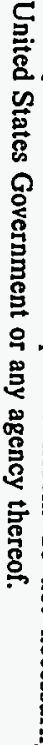

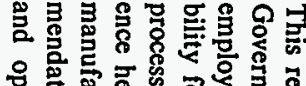

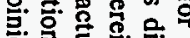

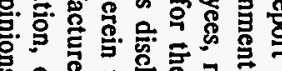

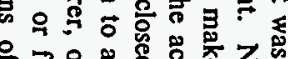

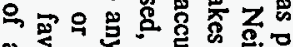

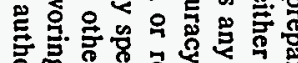

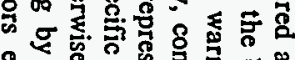

二

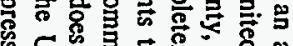

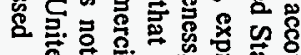

몰

옥 象

용

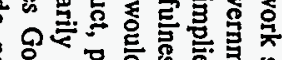

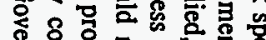

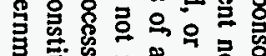

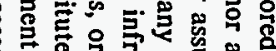

옹요영

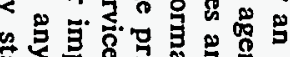

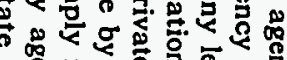

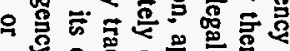

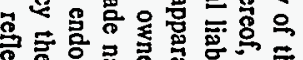

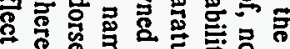

응 可.

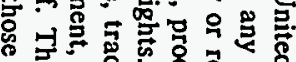

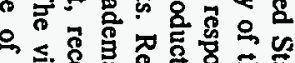

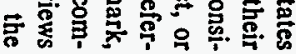

Prepared for the

Interior Department's Bureau of Mines

under Contract No. J0134035

through DOE Idaho Operations Office

Contract DE-AC07-941D13223 
3
4 


\section{DISCLAIMER}

Portions of this document may be illegible in electronic image products. Images are produced from the best available original document. 


\section{ABSTRACT}

This project, Plasma Quench Production of Titanium from Titanium Tetrachloride, centers on developing a technique for rapidly quenching the high temperature metal species and preventing back reactions with the halide. The quenching technique chosen uses the temperature drop produced in a converging/diverging supersonic nozzle. The rapid quench provided by this nozzle prevents the back reaction of the halide and metal. The nature of the process produces nanosized particles $(10$ to $100 \mathrm{~nm})$. The powders are collected by cyclone separators, the hydrogen flared, and the acid scrubbed. Aluminum and titanium powders have been produced in the laboratory-scale device at 1 gram per hour. Efforts to date to scale up this process have not been successful. 



\section{FOREWORD}

This report was prepared by the Department of Energy's Idaho National Engineering Laboratory (INEL) under United States Bureau of Mines (USBM) Contract No. J0134035. As INEL's operating contractor, EG\&G Idaho, Inc. performed the research described herein with portions subcontracted to the University of Idaho. This project, Metal-Gas Reactions in Thermal Plasmas, was initiated under the Minerals and Materials Science Research program and is administered under the technical direction of the Bureau's M\&MS Division. Charles F. Davidson is the Acting Technical Project Officer and Doyne W. Teets is the Contract Officer for USBM. This report is a summary of work completed as part of the contract during the period May 1988 through April 1994; it contains no information considered patentable. This report was submitted in October 1994. 



\section{ACKNOWLEDGMENTS}

The assistance of A. D. Donaldson and B. A. Detering in coordinating this activity with other, concurrent projects is appreciated. Technical consultation, construction, and operational support by T. L. Eddy, J. D. Grandy, P. C. Kong, D. Duford, A. L. Jones, J. E. Lee, P. B. Hembree, and G. C. Wilson were essential to this project. Professors R. Kearney, C. Wai, and J. Park of the University of Idaho provided valuable insight and discussion. The assistance in the preparation of the manuscript by M. M. Siefken is also appreciated. 



\section{CONTENTS}

ABSTRACT $\ldots \ldots \ldots \ldots \ldots \ldots \ldots \ldots \ldots \ldots \ldots \ldots \ldots \ldots \ldots \ldots \ldots \ldots \ldots \ldots \ldots$

FOREWORD $\ldots \ldots \ldots \ldots \ldots \ldots \ldots \ldots \ldots \ldots \ldots \ldots \ldots \ldots \ldots \ldots \ldots$

ACKNOWLEDGMENTS $\ldots \ldots \ldots \ldots \ldots \ldots \ldots \ldots \ldots \ldots \ldots \ldots \ldots \ldots \ldots$ vii

INTRODUCTION $\ldots \ldots \ldots \ldots \ldots \ldots \ldots \ldots \ldots \ldots \ldots \ldots \ldots \ldots \ldots \ldots \ldots$

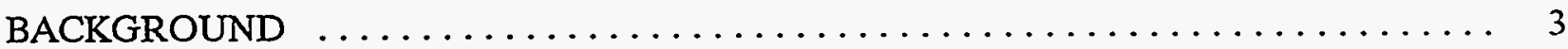

THERMODYNAMIC ANALYSIS $\ldots \ldots \ldots \ldots \ldots \ldots \ldots \ldots \ldots \ldots \ldots$

QÚENCH TECHNOLOGY $\ldots \ldots \ldots \ldots \ldots \ldots \ldots \ldots \ldots \ldots \ldots \ldots \ldots \ldots \ldots$

COMPUTATIONAL FLUID DYNAMIC MODELING $\ldots \ldots \ldots \ldots \ldots \ldots \ldots \ldots \ldots$

EXPERIMENTAL SYSTEM DEVELOPMENTS $\ldots \ldots \ldots \ldots \ldots \ldots \ldots \ldots \ldots$

EXPERIMENTAL PROCEDURE $\ldots \ldots \ldots \ldots \ldots \ldots \ldots \ldots \ldots \ldots \ldots \ldots \ldots \ldots$

ENERGY BALANCE $\ldots \ldots \ldots \ldots \ldots \ldots \ldots \ldots \ldots \ldots \ldots \ldots \ldots \ldots$

ENTHALPY PROBE DIAGNOSTICS $\ldots \ldots \ldots \ldots \ldots \ldots \ldots \ldots \ldots \ldots \ldots \ldots$

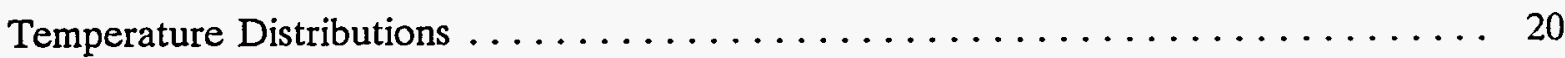

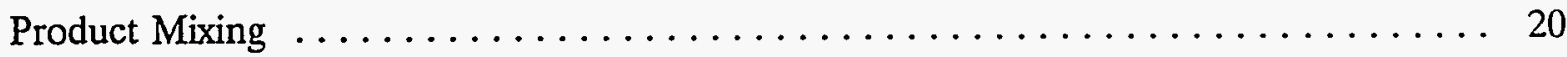

RESULTS AND DISCUSSION $\ldots \ldots \ldots \ldots \ldots \ldots \ldots \ldots \ldots \ldots \ldots \ldots \ldots \ldots \ldots$

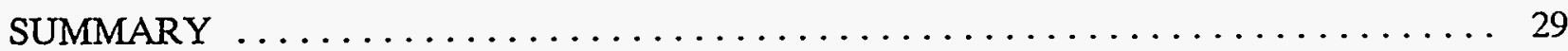

REFERENCES $\ldots \ldots \ldots \ldots \ldots \ldots \ldots \ldots \ldots \ldots \ldots \ldots \ldots \ldots \ldots \ldots \ldots \ldots \ldots$

\section{FIGURES}

1. Graph of the stoichiometric reaction of $\mathrm{H}_{2}$ and $\mathrm{TiCl}_{4}$ based on free energy

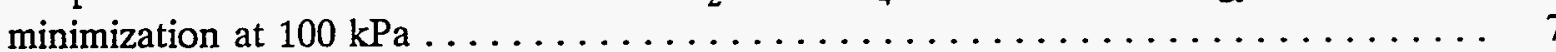

2. Graph of the chemical reaction of $12 x$ stoichiometric $\mathrm{H}_{2}$ and $\mathrm{TiCl}_{4}$ based on the

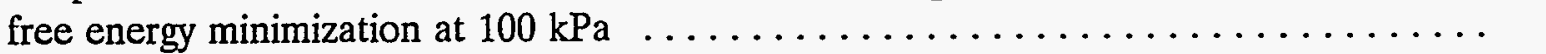

3. Graph of the chemical reaction of $16 \mathrm{x}$ stoichiometric $\mathrm{H}_{2}$ and $\mathrm{TiCl}_{4}$ based on free energy minimization at (a) $10 \mathrm{kPa}$ and (b) $500 \mathrm{kPa}$ pressures 
4. Temperature ratio response for varying pressure ratios for $\gamma$ values of 1.4 and $1.66 \ldots 10$

5. Temperature variations in the plasma quench reactor at $30 \mathrm{~kW}$ power, $24 \mathrm{sLm}$ of Ar flow, and 0.5 moles of $\mathrm{TiCl}_{4}$ in $5 \mathrm{sccm}$ Ar carrier gas $\ldots \ldots \ldots \ldots \ldots \ldots \ldots \ldots$

6. $\mathrm{TiCl}_{4}$ concentration variations in the plasma quench reactor at $30 \mathrm{~kW}$ power, $24 \mathrm{sLm}$ of $\mathrm{Ar}$ flow, and 0.5 moles of $\mathrm{TiCl}_{4}$ in $5 \mathrm{sccm}$ Ar carrier gas $\ldots \ldots \ldots \ldots$

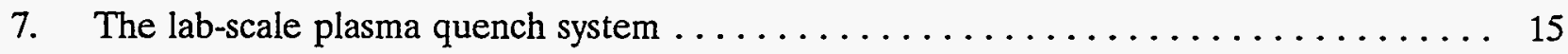

8. Diagram of the plasma quench system $\ldots \ldots \ldots \ldots \ldots \ldots \ldots \ldots \ldots \ldots$

9. $\mathrm{TiCl}_{4}$ injection system used for feeding $<10 \mathrm{~g} / \mathrm{h} \ldots \ldots \ldots \ldots \ldots \ldots \ldots \ldots$

10. Vapor pressure (in atmospheres) of $\mathrm{TiCl}_{4}$ versus temperature based on the

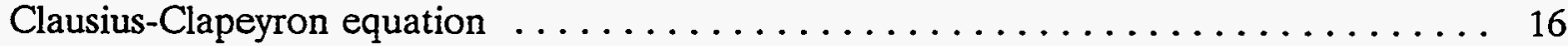

11. $\mathrm{TiCl}_{4}$ injection system used for feeding $>10 \mathrm{~g} / \mathrm{h} \ldots \ldots \ldots \ldots \ldots \ldots \ldots$

12. Energy balance for $\mathrm{TiCl}_{4}$ reduction; $27 \mathrm{sLm}$ Ar plus $2.5 \% \mathrm{H}_{2}$ torch gas, $5 \mathrm{~g} / \mathrm{h} \mathrm{TiCl}_{4}$,

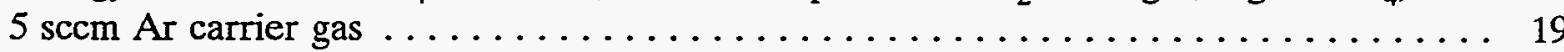

13. Diagram of the enthalpy probe used to determine temperature distributions in the

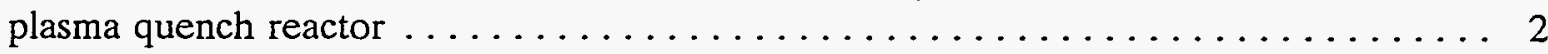

14. Axial temperature distribution in the $16 \mathrm{~mm}$ diameter reactor section operating

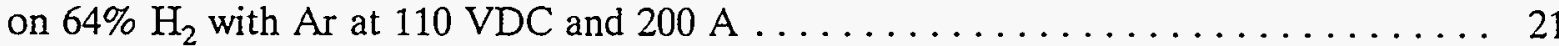

15. Radial temperature distribution in the $16 \mathrm{~mm}$ diameter reactor section operating on $64 \% \mathrm{H}_{2}$ with $\mathrm{Ar}$ at $110 \mathrm{VDC}$ and $200 \mathrm{~A}$ at (a) $160 \mathrm{~mm}$ and (b) $8 \mathrm{~mm} \ldots \ldots . \ldots 22$

16. Diagram of the two test configurations used during the enthalpy probe work $\ldots \ldots \ldots 22$

17. Temperature distribution in the injector and reactor test sections at operating conditions of $77 \% \mathrm{H}_{2}$ with $\mathrm{Ar}$ (total flow-175 scth) with a torch voltage of

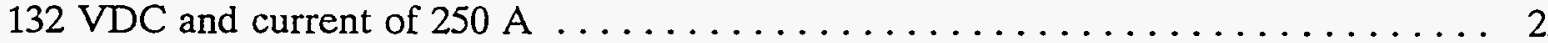

18. V.rupton gas distribution in the injector and reactor section of the plasma quench

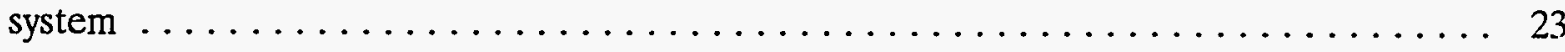

19. SEM micrographs of Ti powder produced by plasma quenching $\ldots \ldots \ldots \ldots \ldots$

20. XRD trace from powder produced during plasma quench run with a very dilute flow of $\mathrm{TiCl}_{4}(<5 \mathrm{~g} / \mathrm{h})$ in an $\mathrm{Ar}$ plasma with $2.5 \% \mathrm{H}_{2}$ indicating an air leak $\ldots . \ldots \ldots$

21. XRD trace from powder produced during plasma quench run with a very dilute flow of $\mathrm{TiCl}_{4}\left(<5 \mathrm{~g} / \mathrm{h}\right.$ ) in an $\mathrm{Ar}$ plasma with $2.5 \% \mathrm{H}_{2}$ (no air leak) $\ldots \ldots \ldots \ldots$ 


\section{TABLE}

1. Metal halides with low boiling points applicable to plasma quench $\ldots \ldots \ldots \ldots$ 


\section{Plasma Quench Production of Titanium from Titanium Tetrachloride}

\section{INTRODUCTION}

The commercial processes for producing titanium metal include the reduction of $\mathrm{TiCl}_{4}$ with sodium (Hunter process) or magnesium (Kroll process). Similar processes are used to reduce UF and $\mathrm{ZrCl}_{4}$. In these processes, the metal is precipitated from the salt solution in the form of sponge, the salt removed, and the metal formed into ingots by vacuum arc remelting. These are batch processes consisting of a sequence of labor-intensive operations that are susceptible to the introduction of impurities that can dramatically affect product quality. A plasma process, using hydrogen reduction of a metal halide, can theoretically be used to produce metal or hydride and result in the direct formation of powder. If successful, this process would have the advantages of continuous operation, reduced labor costs, reduced contamination, and elimination of the need for magnesium or sodium reductants.

Thermal plasma, as applied here, is hot $(>10,000 \mathrm{~K})$ ionized matter produced by passing a gas, or a mixture of two or more gases, through an electric arc. Plasma processes are characterized by high energy density, complete control of oxidation/reduction potential, small volume reactors, high rate of product throughput, low rate of gas throughput, and low capital cost. A hydrogen-argon mixture is heated by a nontransferred DC plasma torch to provide the enthalpy for the reaction:

$\mathrm{TiCl}_{4}+2 \mathrm{H}_{2} \rightarrow \mathrm{Ti}+4 \mathrm{HCl}$

at temperatures above $5000 \mathrm{~K}$.

The objective of this project was to develop a bench-scale process that could be scaled up for the hydrogen reduction of $\mathrm{TiCl}_{4}$ to $\mathrm{Ti}$ metal using the plasma quench process. Plasma quench processing uses a converging/diverging (DeLaval) nozzle to rapidly quench high temperature plasma reactants, permitting high-yield production of nonequilibrium products. At $5000 \mathrm{~K}$ the converging/diverging nozzle produces quench rates of over ten million degrees per second, preventing back reactions that would form $\mathrm{TiCl}_{3}$ and $\mathrm{TiCl}_{2}$. At these temperatures the reactants, $\mathrm{TiCl}_{4}$ and $\mathrm{H}_{2}$, are completely dissociated into titanium vapor, hydrogen, and chlorine. The process has been demonstrated for the production of $\mathrm{Ti}$ metal from $\mathrm{TiCl}_{4}$ on the laboratory scale, but has been difficult to scale up. An effort is underway at the Idaho National Engineering Laboratory to demonstrate the process on $\mathrm{UF}_{6}$ at the lab scale $(<25 \mathrm{~g} / \mathrm{h})$.

The plasma quench process is continuous and has a small working volume reactor, so little reactant undergoes reaction at a given time. Residence time in the reactor is on the order of milliseconds. The product can be synthesized as a hydride, a more stable form to handle than 
fine, titanium metal powder. ${ }^{a}$ The titanium hydride can be subsequently converted into metal. Also, hydrogen is a less expensive reducing agent than sodium or magnesium, and can be easily recycled.

The plasma quench technology was designed and successfully tested at the Idaho National Engineering Laboratory in June 1990. At that time, the plasma quench device was able to produce approximately $0.5 \mathrm{~g} / \mathrm{h}$ of submicron Ti powder with a plasma electrical power input of $10 \mathrm{~kW}$. The plasma gas for those and subsequent experiments was a mixture of $95 \%$ argon and $5 \%$ hydrogen. Argon gas is inert but does help push the reaction to the right due to Le Chatelier's principle. Improvements in the theoretical understanding of the quench process, quench reactor design, and reactant injection are needed to increase production levels above $1 \mathrm{~g} / \mathrm{h}$.

a. Private conversation with Prof. R. Kearney, University of Idaho, December 1993. 


\section{BACKGROUND}

Plasma processing of metal halides has been the subject of various research programs spanning the last 30 years. The plasma processes, either nontransferred arc or radio frequency induced ( $\mathrm{RF}$ ), produce temperatures over $5000 \mathrm{~K}$. At these temperatures, metal halides are completely dissociated and become free species. Research has been mainly focused on the reactions that form oxides, nitrides, and carbides from the metal halide. Metal halides are particularly of interest because their low boiling points allow them to react in gaseous form. The production of pure metal from its halide is more difficult and little success has been achieved because of back reactions with the halide. It has been identified by a number of researchers ${ }^{1,2,3,4, b}$ that a rapid quench is an essential step to produce metal from its halide. It has been concluded that quench rates on the order of $10^{9}$ to $10^{10} \mathrm{~K} / \mathrm{s}$ are required to "freeze" the metal and prevent back reactions.

The plasma quench process is theoretically applicable to the reduction of any volatile metal halide. Table 1 gives examples of a few metal halides that are easily volatilized and are candidates for reduction by plasma quench to produce pure metal, alloys, carbides, nitrides, or oxides. At temperatures in excess of $5000 \mathrm{~K}$ most of these compounds dissociate into their elements (the Gibbs free energy of formation becomes positive). Quenching the elements rapidly from this temperature results in the formation of halide gas and metal,

$M_{y} G_{x}-M+\frac{x}{2} G_{2}$

where $\mathrm{M}$ is the metal species ( $\mathrm{Al}, \mathrm{B}, \mathrm{Be}$, etc.) and $\mathrm{G}$ is the halide gas $(\mathrm{Cl}$ or $\mathrm{F})$. With addition of hydrogen to the equation, more stable species may be formed,

$M_{y} G_{x}+H_{2} \rightarrow{ }_{y} M($ or $M H)+{ }_{x} H G$

such as hydrides and acids $\left(\mathrm{TiH}_{2}, \mathrm{HCl}\right.$ and $\left.\mathrm{HF}\right)$. Oxygen, anhydrous ammonia, or methane can be used to replace the hydrogen gas in the equation above in order to form the respective oxides, nitrides, or carbides.

Neuenschwander reported on the synthesis of $\mathrm{TaC}, \mathrm{NbC}, \mathrm{TiC}, \mathrm{TaN}$ and $\mathrm{W}$ in hydrogen plasmas in 1966..$^{5}$ In 1975, Tumanov and Galkin ${ }^{1}$ described the efforts to produce uranium metal from $\mathrm{UF}_{6}$ and $\mathrm{H}_{2}$ in a plasma generator. Examples of industrial plasma synthesis include the production of $\mathrm{TiO}_{2}$ from $\mathrm{TiCl}_{4}$ for use as paint pigment (TiOxide, LTD, U. K. ${ }^{6.7}$ ) and the production of acetylene from methane (Hüls $\mathrm{AG}$, Germany $^{8}$ ). Researchers in Japan, Russia, Canada, and England have also investigated reduction technologies for $\mathrm{TiCl}_{4}$ to titanium metal. ${ }^{9}$ The Electricity Council Research Center, Capenhurst, England, studied plasma reduction of titanium tetrachloride to titanium. Their equilibrium studies indicated that complete conversion

b. Discussions with R. Laviolette and R. Berry, Idaho National Engineering Laboratory, November 1993. 
Table.1. Metal halides with low boiling points applicable to plasma quench.

\begin{tabular}{|c|c|c|c|c|}
\hline Compound & $\begin{array}{l}\text { Molecular weight } \\
\text { (g) }\end{array}$ & $\begin{array}{l}\text { Density } \\
\left(\mathrm{g} / \mathrm{cm}^{3}\right)\end{array}$ & $\begin{array}{c}\text { Melting point } \\
\left({ }^{\circ} \mathrm{C}\right)\end{array}$ & $\begin{array}{c}\text { Boiling point } \\
\left({ }^{\circ} \mathrm{C}\right)\end{array}$ \\
\hline $\mathrm{AlCl}_{3}$ & 133.34 & 2.44 & 190 & $180 \mathrm{subl}$ \\
\hline $\mathrm{AlI}_{3}$ & 407.69 & 3.98 & 191 & 360 \\
\hline $\mathrm{SbBr}_{3}$ & 361.48 & 4.148 & 96.6 & 280 \\
\hline $\mathrm{SbCl}_{5}$ & 216.74 & 2.99 & 2.8 & 79 \\
\hline $\mathrm{SbF}_{5}$ & 178.75 & 4.379 & 7 & 149.5 \\
\hline $\mathrm{SbI}_{5}$ & 756.27 & & 79 & 400.6 \\
\hline $\mathrm{BeCl}_{2}$ & 79.92 & 1.899 & 405 & 520 \\
\hline $\mathrm{BeF}_{2}$ & 47.01 & 1.986 & 800 subl & \\
\hline $\mathrm{BeI}_{2}$ & 262.82 & 4.325 & 510 & 590 \\
\hline $\mathrm{BCl}_{3}$ & 117.17 & 1.349 & -107.3 & 12.5 \\
\hline $\mathrm{BF}_{3}$ & 67.81 & 2.99 & -126.7 & -99.9 \\
\hline $\mathrm{BI}_{3}$ & 391.52 & 3.35 & 49.9 & 210 \\
\hline $\mathrm{GaCl}_{3}$ & 176.03 & 2.47 & 77.9 & 201.3 \\
\hline $\mathrm{MoCl}_{5}$ & 273.21 & 2.928 & 194 & 268 \\
\hline $\mathrm{MoF}_{6}$ & 209.93 & 2.55 & 17.5 & 35 \\
\hline $\mathrm{NbCl}_{5}$ & 270.17 & 2.75 & 204.7 & 254 \\
\hline $\mathrm{NbF}_{5}$ & 187.9 & 3.293 & 73 & 236 \\
\hline $\mathrm{PuF}_{6}$ & 355.99 & & 50.75 & 62.3 \\
\hline $\operatorname{ReF}_{6}$ & 300.19 & 6.1573 & 18.8 & 47.6 \\
\hline $\mathrm{SiCl}_{4}$ & 169.9 & 1.483 & -70 & 57.57 \\
\hline $\mathrm{Si}_{2} \mathrm{~F}_{6}$ & 170.16 & $77.59 \mathrm{~g} / \mathrm{L}$ & -18.7 & -18.5 \\
\hline $\mathrm{TaCl}_{5}$ & 358.21 & 3.68 & 216 & 242 \\
\hline $\mathrm{TaF}_{5}$ & 275.94 & 4.74 & 96.8 & 229.5 \\
\hline $\mathrm{TeCl}_{4}$ & 269.41 & 3.26 & 224 & 380 \\
\hline $\mathrm{TeF}_{6}$ & 241.59 & 4.006 & -36 & 35.5 \\
\hline $\mathrm{TiCl}_{4}$ & 189.71 & 1.726 & -25 & 136.4 \\
\hline$W_{6}$ & 297.84 & $12.9 \mathrm{~g} / \mathrm{L}$ & 2.5 & 17.5 \\
\hline $\mathrm{UF}_{6}$ & 352.02 & 4.68 & 64.8 & 56.2 \\
\hline $\mathrm{VCl}_{4}$ & 192.75 & 1.816 & -28 & 148.5 \\
\hline $\mathrm{ZrCl}_{4}$ & 233.03 & 2.803 & 437 & 331 subl \\
\hline
\end{tabular}


of $\mathrm{TiCl}_{4}$ by hydrogen is impossible, while sodium reduction will result in $100 \%$ conversion at $2000 \mathrm{~K}^{2}$. Development of the sodium vapor reduction process was impeded by difficulties in obtaining steady, controlled feed of the reactant materials. ${ }^{10}$ Gauvin demonstrated the technical feasibility of a plasma process for the thermal decomposition of zirconium tetrachloride and titanium tetrachloride. ${ }^{11,12}$ Recently, patent applications were filed for these processes. ${ }^{13}$ The primary difficulty in the plasma processes has been inability to obtain an acceptable yield in the absence of a metal reductant. Recycling the unreacted tetrachloride and partially reduced subchlorides is feasible but must be kept to a minimum for acceptable energy efficiency. $\mathrm{MacRae}^{\mathrm{c}}$ examined this process as early as 1971 and confirmed the problems of low conversion and subchloride production. There has been comparable work on the $\mathrm{ZrCl}_{4}$ and $\mathrm{SiCl}_{4}$ systems. Recently, a report from South Africa focused on the $\mathrm{H}_{2}$ reduction of $\mathrm{UF}_{6}$ to $\mathrm{UF}_{4}$ in a thermal plasma. ${ }^{14}$ However, these processes did not involve the use of a DeLaval nozzle to rapidly quench plasma reactants to obtain metal products as was the goal of this project.

c. D. R. MacRae, private communication, Bethlehem Steel, January 1988. 


\section{THERMODYNAMIC ANALYSIS}

Generation of supersaturated mixtures of vapor products is possible as the gas cools, leading to the formation of nanocrystalline particles by homogeneous nucleation. When the nucleation step is followed by rapid quenching, the desired products are solidified so that the high temperature condensed phase remains instead of being consumed by back reactions predicted by equilibrium thermodynamics. Deviations from equilibrium occur because gas-solid and gas-liquid reactions generally take place at lower rates than gas-phase reactions since they are diffusion dependent. During rapid quenching, significant deviations from equilibrium can be obtained because the time available for diffusion and reaction are limited. This phenomenon is similar to rapid solidification effects that occur during quenching from the liquid phase in the production of metal powders. ${ }^{15}$ Thus, the chemistry and particle size can be controlled to some extent by manipulating the quenching rates of the vapor phase by gas dynamics ${ }^{3}$ and/or by the injection of cold quench gas. ${ }^{16}$

Free energy minimization analysis of the equilibrium chemistry for $\mathrm{TiCl}_{4}$ in $\mathrm{H}_{2}$ and $\mathrm{Ar}$ gases was performed using the OUTOKUMPU ${ }^{17}$ code. Analyses of effects of reaction pressure and excess $\mathrm{H}_{2}$ and $\mathrm{Ar}$ on the reaction were performed. The inert gas additions affect the extent of reactions in a manner similar to Le Châtelier's principle. When the net number of moles going from reactants to products increases, the product yield is increased with decreasing pressure. Inert gas addition reduces the relative net increase in mole number, which has an effect similar to reducing the total system pressure. ${ }^{4}$ Thus, when the net change in the number of moles is positive, inert gas dilution will increase the yield.

The stoichiometric relationship between $\mathrm{Ti}, \mathrm{H}_{2}$, and $\mathrm{TiCl}_{4}$ is given in Equation 1. The equilibrium composition diagram for the system with an initial molar ratio of $1 \mathrm{~mol}$ of $\mathrm{TiCl}_{4}$ and $2 \mathrm{~mol}$ of $\mathrm{H}_{2}(\mathrm{H}: \mathrm{Cl}=1: 1)$ at $100 \mathrm{kPa}$ is depicted in Figure 1 for temperatures between 500 and $6500 \mathrm{~K}$. Above $4500 \mathrm{~K}$ the predominant species are $\mathrm{Ti}_{(\mathrm{g})}, \mathrm{H}_{(\mathrm{g})}$, and $\mathrm{Cl}_{(\mathrm{g})}$. Titanium gas approaches 1 mole at temperatures above $5200 \mathrm{~K}$ for the stoichiometric composition. Increasing the $\mathrm{H}: \mathrm{Cl}$ ratio to $12: 1$ decreases the $100 \%$ conversion point by 900 to $4300 \mathrm{~K}$ as shown in Figure 2. Pressure also has a significant effect on the equilibrium concentration of Ti. Figures 3a and $3 \mathrm{~b}$ show the curve shift for a $16: 1 \mathrm{H}: \mathrm{Cl}$ ratio due to pressure changes. Titanium reaches 1 mole for $10 \mathrm{kPa}$ pressure at about $3200 \mathrm{~K}$, while at $500 \mathrm{kPa}$ with the same gas composition the temperature required is $4800 \mathrm{~K}$. Argon is not represented as a species in these reactions, but contributes by reducing the effective pressure.

Changes in the equilibrium free energy curves caused by pressure, inert gas content, and excess $\mathrm{H}_{2}$ are important in the plasma qurn nh process. Deviations from stoichiometric chemistry (excess $\mathrm{H}_{2}$ ) lead to higher energy costs since the extra gas needs to be heated, but lower temperatures are required for the reaction. Introducing inert gas reduces the elfective pressure of the reaction but decreases efficiency by requiring extra gas heating. 


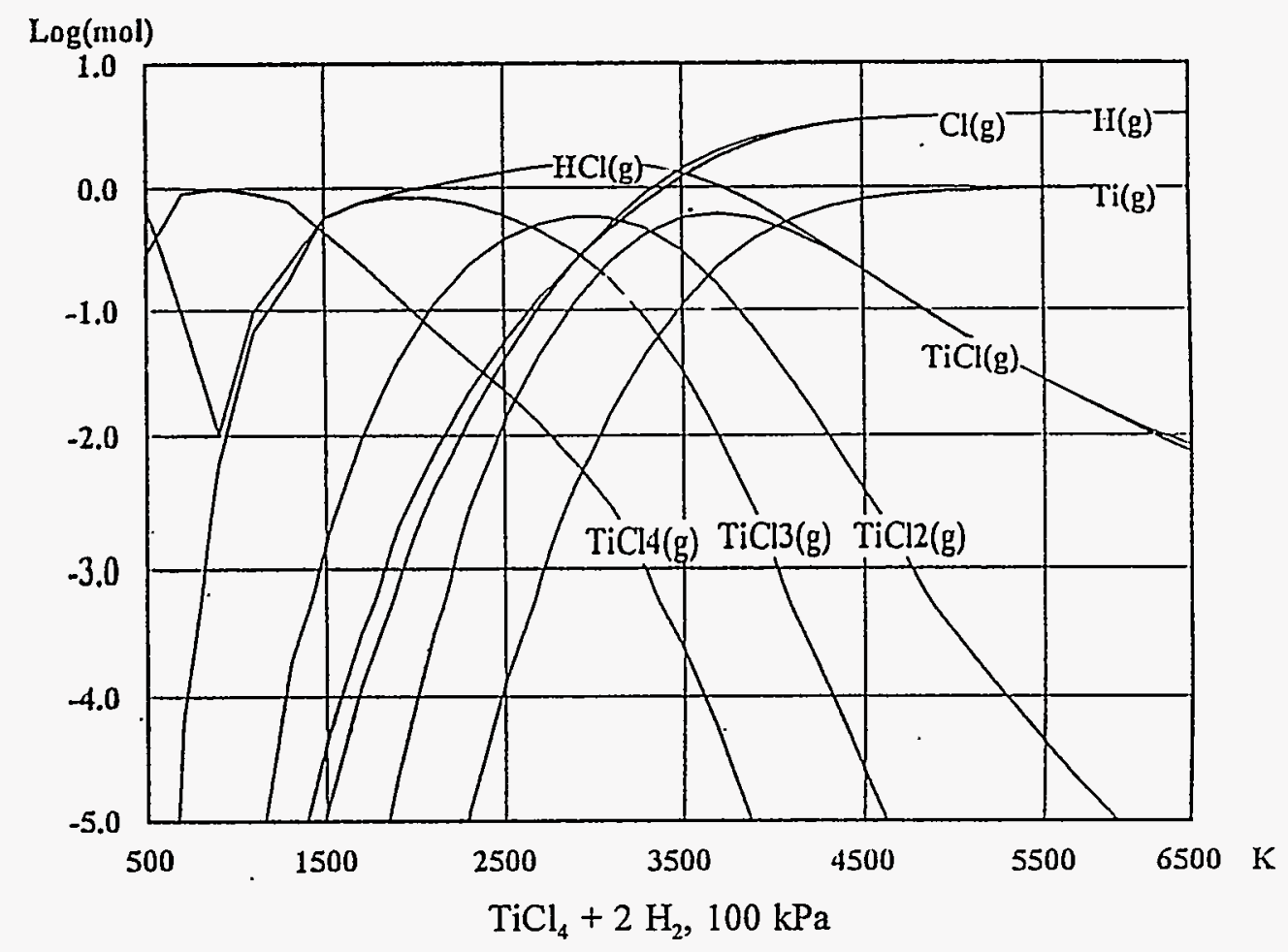

Figure 1. Graph of the stoichiometric reaction of $\mathrm{H}_{2}$ and $\mathrm{TiCl}_{4}$ based on free energy minimization at $100 \mathrm{kPa}$.

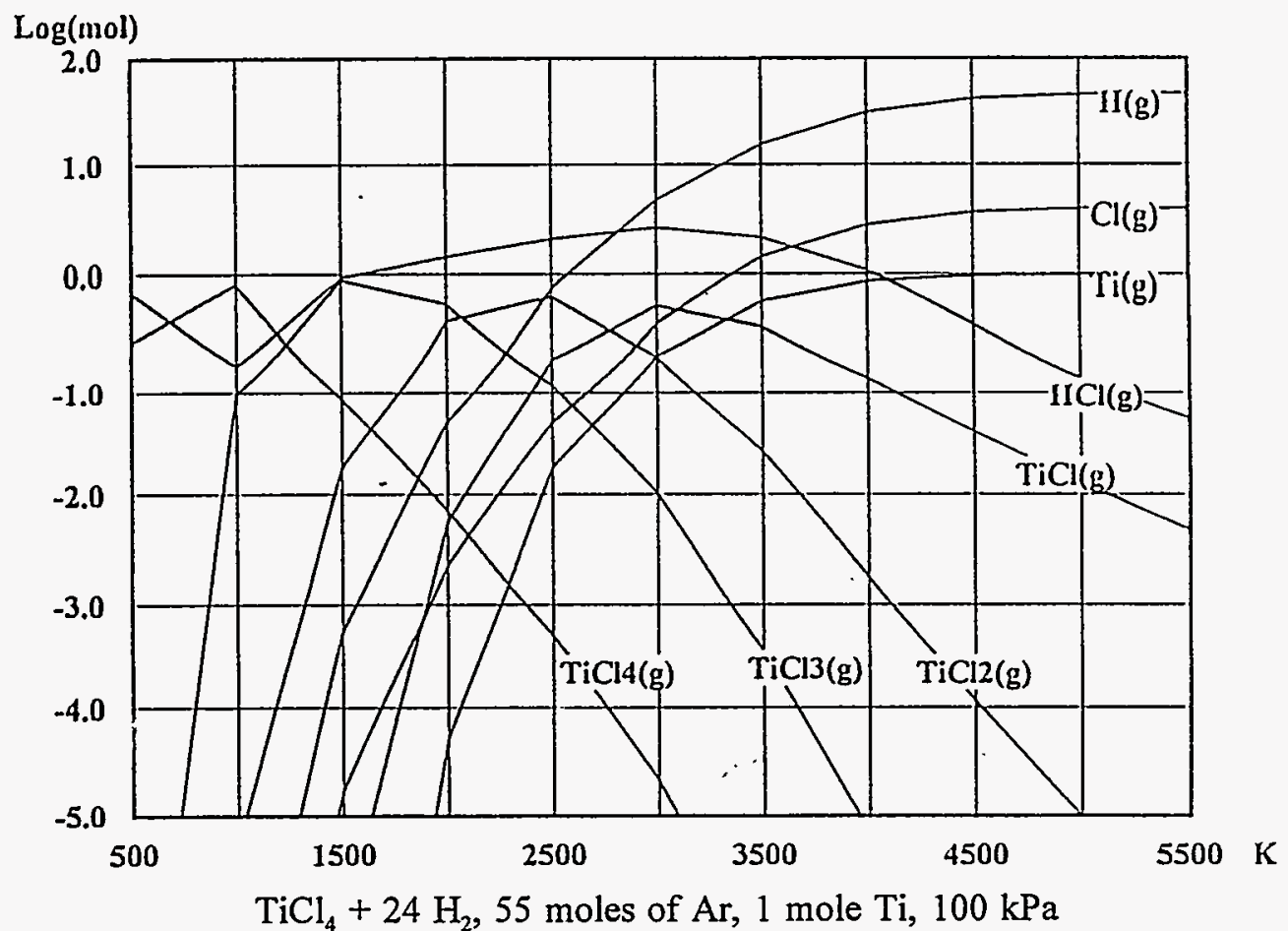

Figure 2. Graph of the chemical reaction of $12 \mathrm{x}$ stoichiometric $\mathrm{H}_{2}$ and $\mathrm{TiCl}_{4}$ based on the free energy minimization at $100 \mathrm{kPa}$. 


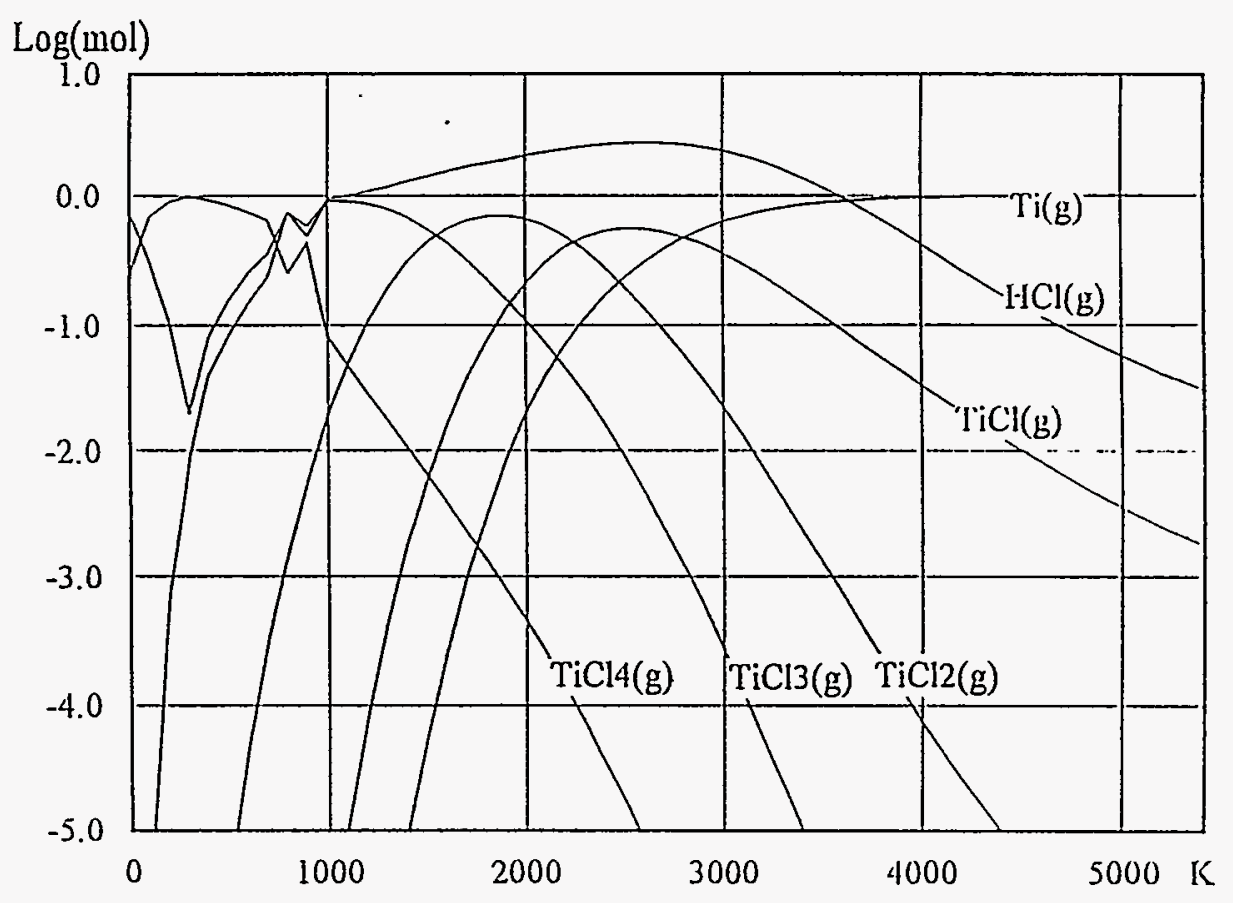

a. $\mathrm{TiCl}_{4}+32 \mathrm{H}_{2}, 10 \mathrm{kPa}$

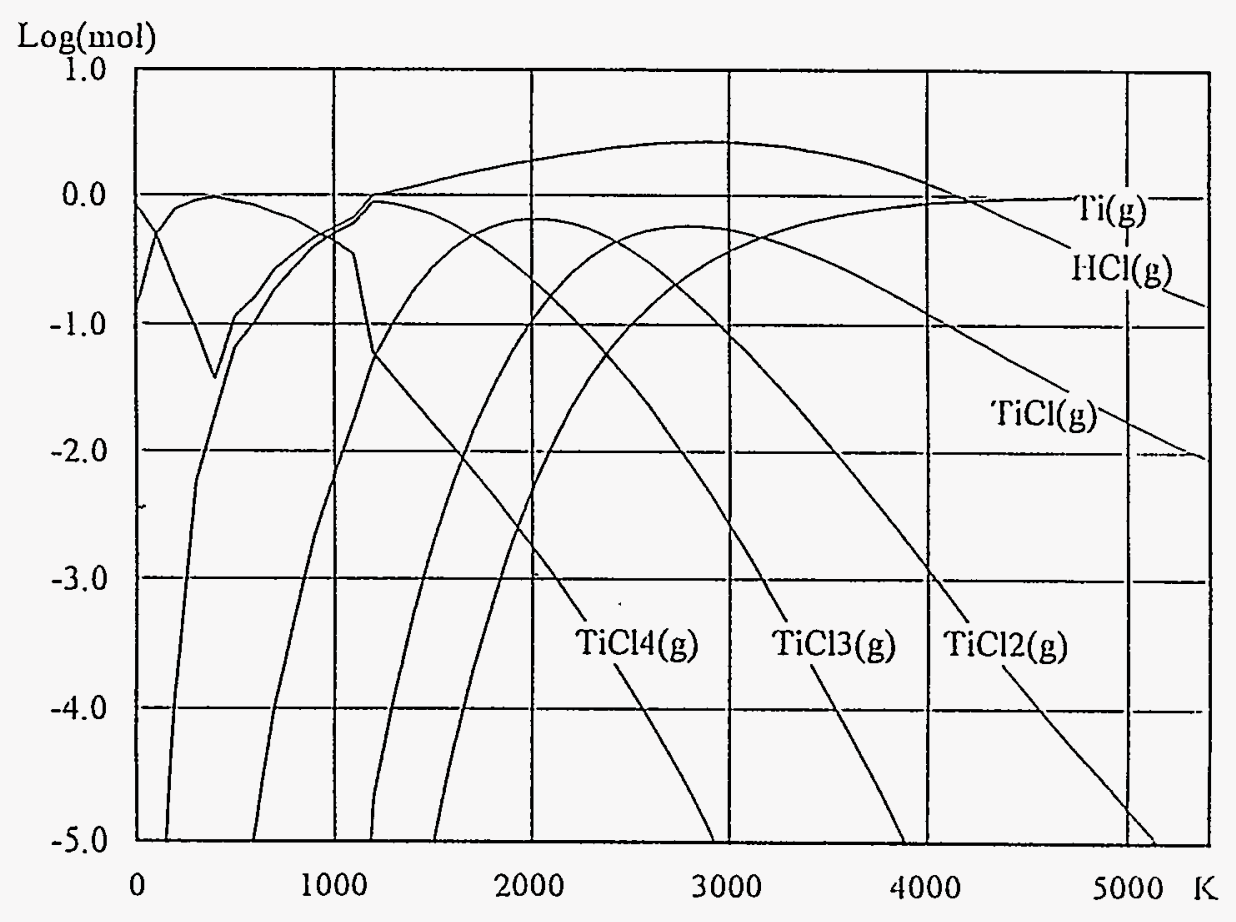

b. $\mathrm{TiCl}_{4}+32 \mathrm{H}_{2}, 500 \mathrm{kPa}$

Figure 3. Graph of the chemical reaction of $16 x$ stoichiometric $\mathrm{H}_{2}$ and $\mathrm{TiCl}_{4}$ based on free energy minimization at (a) $10 \mathrm{kPa}$ and (b) $500 \mathrm{kPa}$ pressures. 


\section{QUENCH TECHNOLOGY}

For isentropic processes, the temperature drop resulting from an adiabatic expansion in a converging/diverging nozzle is given for an ideal gas with constant specific heat by: ${ }^{18}$

$$
\left(\frac{P_{0}}{P_{1}}\right)^{\frac{\gamma-1}{\gamma}}=\frac{T_{0}}{T_{1}} .
$$

The $\gamma$ is the ratio of $C_{p} / C_{v}$ (where $C_{p}$ and $C_{v}$ are the heat capacities at constant pressure and constant volume, respectively); $\gamma$ is 1.66 for argon and 1.4 for hydrogen and hydrogen chloride. The heat capacity ratio equals 1.66 for monatomic gases and 1.4 for polyatomic gases. Equation 4 for $\gamma=1.66$ and 1.4 is graphed in Figure 4. $P_{0}, P_{1}, T_{0}$, and $T_{1}$ are initial and final pressures and temperatures, respectively. Since most diatomic and polyatomic gases are dissociated at $5000 \mathrm{~K}$ into monatomic gases, $\gamma$ is probably closer to 1.66 during the initial portion of the quench. In the current system, the reactor inlet pressure is $200 \mathrm{kPa}$ and nozzle exit pressure is $10 \mathrm{kPa}$ for a pressure ratio of $20: 1$; this results in a temperature ratio of $3: 1$. For true adiabatic conditions, the final temperature of the gas exiting the nozzle should be $1670 \mathrm{~K}$. However, due to cold walls and the injection of cold gas, the actual temperature of the exit gas is much lower.

The cooling rate for a volume of gas passing through a nozzle reaches a maximum practically at the throat. For a two-dimensional (planar flow) nozzle flow, the radius of curvature of the nozzle inlet $\left(\mathrm{R}^{*}\right)$ and the throat height $\left(\mathrm{h}^{*}\right)$ are the major design parameters. The cooling rate of the gas is determined by the equation:

$$
\left(\frac{d\left(\frac{T}{T_{0}}\right)}{d t}\right)^{*}=-c a_{0}\left(R^{*} h^{*}\right)^{-1 / 2}
$$

where $a_{o}$ is the speed of sound at the nozzle supply and $c$ is a constant based on $\gamma$ for the gas. For argon at $5000 \mathrm{~K}, \mathrm{c}=0.38, \mathrm{a}_{\mathrm{o}}=1317 \mathrm{~m} / \mathrm{s}, \mathrm{h}^{*}=3.5 \mathrm{~mm}$, and $\mathrm{R}^{*}=2 \mathrm{~mm}$ results in a cooling rate of about $10^{9} \mathrm{~K} / \mathrm{s}$. 


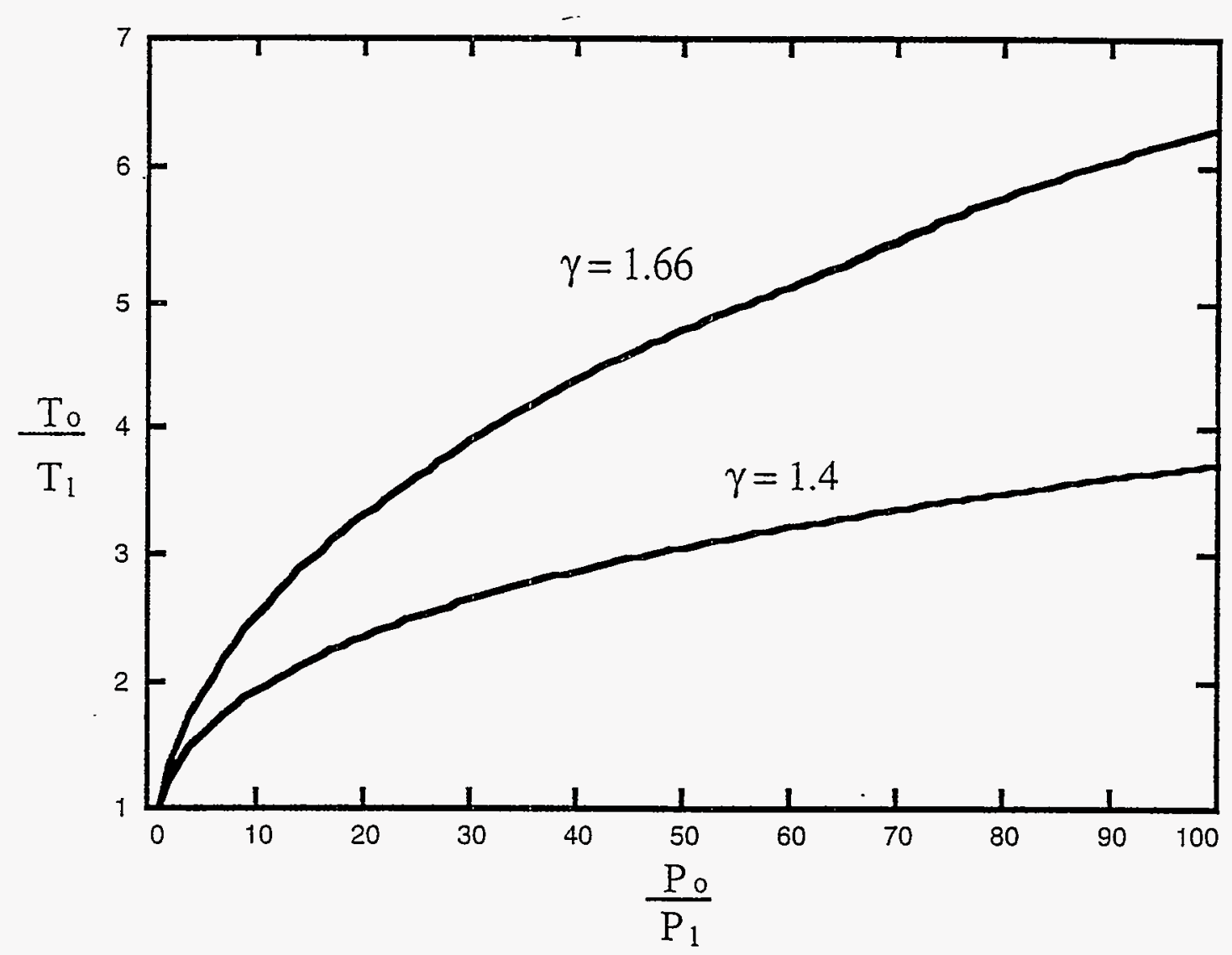

Figure 4. Temperature ratio response for varying pressure ratios for $\gamma$ values of 1.4 and 1.66. 


\section{COMPUTATIONAL FLUID DYNAMIC MODELING}

A three-dimensional multiple-zoned implicit Navier-Stokes code with very general capabilities was used to model the mixing of $\mathrm{TiCl}_{4}$ in argon plasma at $5000 \mathrm{~K}$. The code solves the Reynolds-averaged Navier-Stokes equations (equations of motion of a viscous fluid) with userspecified chemistry and choice of two turbulence models. Chemically reacting flows in thermal nonequilibrium are modeled by including an additional conservation equation for each of the species constituents and for the vibrational and electronic energy of the molecules. Additional features of the code include surface radiation and slip-wall boundary conditions for low density flows. A wide range of inflow, outflow, and wall boundary conditions are available to model the complex 3D flow fields. The code has been used to study shock-induced combustion phenomena and to simulate a ram accelerator.

The plasma quench reactor system for the conversion of $\mathrm{TiCl}_{4}$ to $\mathrm{Ti}$ and $\mathrm{HCl}$ consists essentially of a plasma torch-driven reaction chamber in which $\mathrm{TiCl}_{4}$ is cracked into its elemental constituents, and a converging-diverging nozzle through which the high temperature gaseous mixture passes to produce a rapid temperature quench, freezing the chemical state with atomic $\mathrm{Ti}$ (plus other constituents). As the low temperature is maintained, the atomic Ti condenses in flight to produce Ti particles. The problem has all of the essential features of a reacting hypersonic flow: high temperature, high velocity, chemical reactions, dissociation-recombination, ionization, and thermal nonequilibrium. Although the code was originally written with hypersonic, aerospace applications in mind, its general features make it well suited for this application. A method to determine particle nucleation and growth can be formulated when coupled with the nucleation simulation techniques described by Laviolette. ${ }^{\mathrm{b}}$

Temperature variations in the plasma quench reactor for $30 \mathrm{~kW}$ power level, $24 \mathrm{sLm}$ of $\mathrm{Ar}$ torch gas flow, and 0.5 moles of $\mathrm{TiCl}_{4}$ in $5 \mathrm{sccm}$ Ar carrier gas are shown in Figure 5 . The shaded areas indicate temperatures in excess of $5000 \mathrm{~K}$. A $1000 \mathrm{~K}$ boundary condition is maintained for the reactor walls. In this model, the injection point is simulated by an annulus of similar cross-sectional area. Under these conditions, temperatures of over $5000 \mathrm{~K}$ are maintained to the nozzle throat entrance except in the area immediately adjacent to the injection annulus. $\mathrm{TiCl}_{4}$ concentration variations in the plasma quench reactor for $30 \mathrm{~kW}$ power level, $24 \mathrm{sLm}$ of $\mathrm{Ar}$ torch gas flow, and 0.5 moles of $\mathrm{TiCl}_{4}$ in $5 \mathrm{sccm}$ Ar carrier gas are shown in Figure 6. The dark, shaded areas indicate high concentrations of $\mathrm{TiCl}_{4}$. The same thermal boundary conditions, injection conditions, and mass flow are maintained as described above for Figure 5. Under these conditions, the concentration of $\mathrm{TiCl}_{4}$ vapor migrates towards the centerline of the gas flow. High concentrations of $\mathrm{TiCl}_{4}$ are not found in the boundary layer of the gas flow; this indicates that most of the $\mathrm{TiCl}_{4}$ and its components, $\mathrm{Ti}$ and $\mathrm{Cl}$, are found in the central flow streams as they approach the nozzle. 


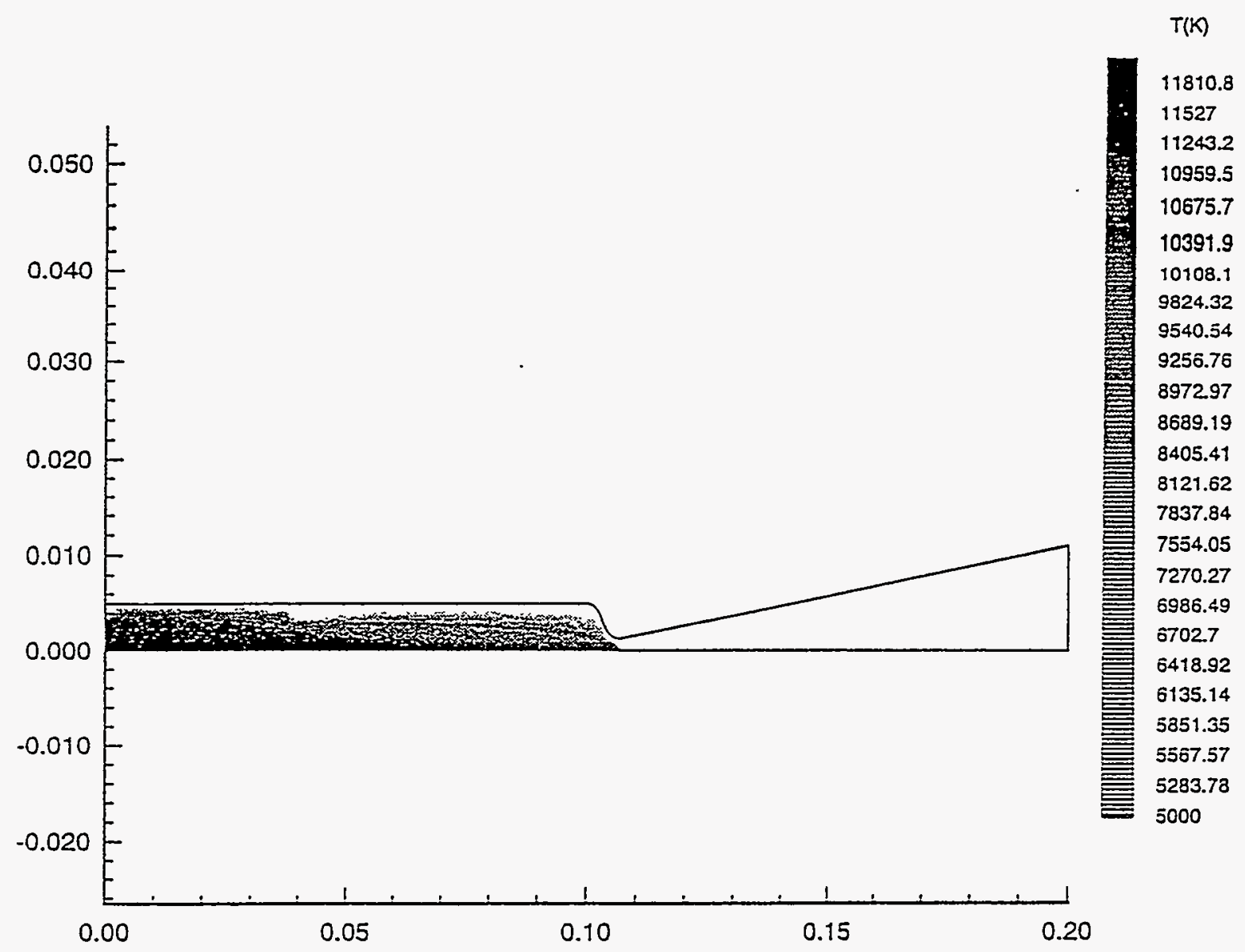

Figure 5. Temperature variations in the plasma quench reactor at $30 \mathrm{~kW}$ power, $24 \mathrm{sLm}$ of $\mathrm{Ar}$ flow, and 0.5 moles of $\mathrm{TiCl}_{4}$ in $5 \mathrm{sccm} \mathrm{Ar} \mathrm{carrier} \mathrm{gas.}$ 


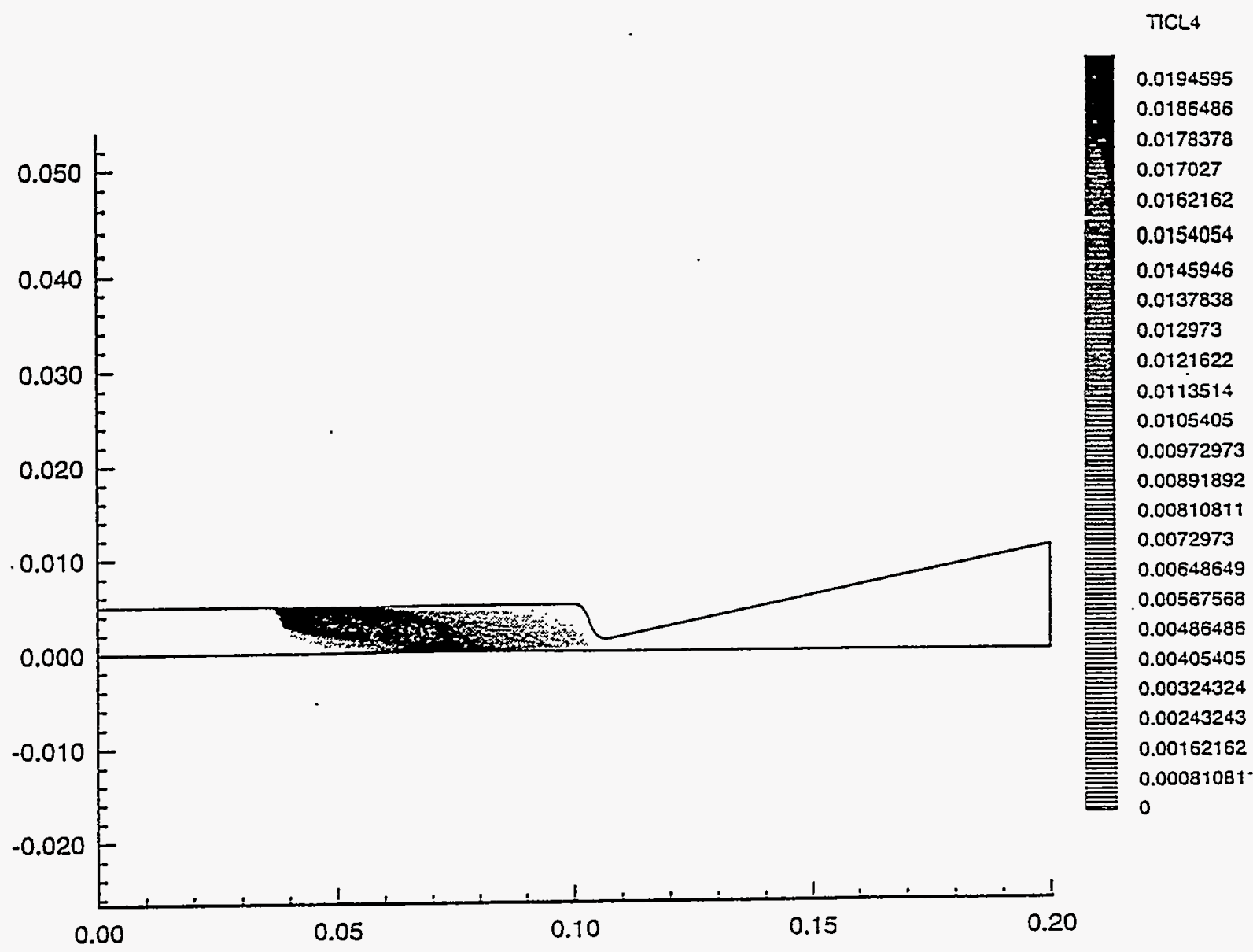

Figure 6. $\mathrm{TiCl}_{4}$ concentration variations in the plasma quench reactor at $30 \mathrm{~kW}$ power, $24 \mathrm{sLm}$ of Ar flow, and 0.5 moles of $\mathrm{TiCl}_{4}$ in $5 \mathrm{sccm} \mathrm{Ar} \mathrm{carrier} \mathrm{gas.}$ 


\section{EXPERIMENTAL SYSTEM DEVELOPMENTS}

The plasma quench system, shown in Figure 7, uses an electric arc to create a high temperature thermal plasma that heats the reactants above their decomposition temperatures. Argon gas is fed into a $30 \mathrm{~kW}$ hot tungsten cathode, nontransferred arc plasma torch. This gas is heated to over $15,000 \mathrm{~K}$ within the arc of the torch. The plasma gas exiting the torch contains the enthalpy and temperature to heat and dissociate the reactants. At $5000 \mathrm{~K}, 1743 \mathrm{~kJ} / \mathrm{mol}$ is required for the reaction and $1571 \mathrm{~kJ} / \mathrm{h}$ for heating the carrier gas. At a leed rate of 0.25 moles of $\mathrm{TiCl}_{4}$ per hour, the total energy burden of the injection mixture is $2000 \mathrm{~kJ} / \mathrm{h}$.

The titanium tetrachloride feed is forced out of a containment bottle with Ar gas pressure; a needle valve controls its flow into a heated tube furnace. In the furnace, the $\mathrm{TiCl}_{4}$ vapor is mixed with argon gas (which acts as a carrier into the plasma) at greater than $200^{\circ} \mathrm{C}$ and $500 \mathrm{kPa}$. The $\mathrm{TiCl}_{4}-\mathrm{Ar}$ mixture, injected into the plasma gas at the exit of the plasma torch, are heated by the plasma gas to temperatures above $5000 \mathrm{~K}$, where hydrogen is monatomic and $\mathrm{TiCl}_{4}$ dissociates. The reactor allows sufficient residence time for decomposition. The hot gas mixture then enters the nozzle where rapid cooling takes place and velocities increase to supersonic. Upon exiting the nozzle, $\mathrm{H}_{2}$ gas is introduced to prevent reheating of the gas mixture as it returns to subsonic flow. The adiabatic $-\mathrm{H}_{2}$ gas quench achieves cooling rates on the order of $10^{9 \cdot} \mathrm{C} / \mathrm{s}$ which "lreeze out" the desired products before they have time to back react with co-product gases $(\mathrm{HCl}$ in this case). Titanium is homogeneously nucleated in the throat section as $10 \mathrm{~nm}$ particles that agglomerate into $0.1 \mathrm{~mm}$ clusters downstream. The titanium powder product is collected in a series of high efficiency cyclones, hydrochloric acid is collected by reacting with $\mathrm{NaOH}$ in solution, and hydrogen is flared after exiting the downstream water-seal vacuum pump. A diagram of the plasma quench system is shown in Figure 8.

Hydrogen is both a coolant and reductant in the process, and retards oxidation reactions. Experimental work has shown that high temperature dissociation of $\mathrm{TiCl}_{4}$, rapid cooling, and $\mathrm{H}_{2}$ stabilization are critical to prevent back reactions of titanium with chloride ions to form titanium chlorides $\left(\mathrm{TiCl}_{\mathrm{x}}, \mathrm{x}=1,2,3\right)$. The quenching step makes the process much simpler and inherently less capital intensive than the Kroll or Hunter processes.

One of the major problems with the system was the ability to accurately control $\mathrm{TiCl}_{4}$ injection. Since the feed rates are very low $(<1 \mathrm{sccm})$, and small injector nozzles are used, feed system plugging frequently occurred. Initial work on injection used low pressure $\left(<200^{-} \mathrm{kPa}\right)$ argon or hydrogen saturated with $\mathrm{TiCl}_{4}$ vapor to produce feed rates of less than a gram per hour. The use of heaters to vaporize the $\mathrm{TiCl}_{4}$ and heat the injection line was partially successful but the liquid flow controller limited the pressure of the feed to less than $200 \mathrm{kPa}$. It was felt that higher velocities were needed to obtain the momentum necessary to penetrate the highly viscous plasma. Pressures on the order of $500 \mathrm{kPa}$ produce sufficient velocities for ir ${ }^{*} \cdots$ on when injector nozzle diameters of 0.010 to $0.020 \mathrm{in}$. are used. To satisfy the need for high velocities and low feed rates, two injection systems were developed, one for feed rates of $<10 \mathrm{~g} / \mathrm{h} \mathrm{of} \mathrm{TiCl}_{4}$ and the other for feed rates $>10 \mathrm{~g} / \mathrm{h}$.

The components of the injection system are shown in Figure 9. Argon carrier gas is supplied to the $\mathrm{TiCl}_{4}$ pressure bottle through an $\mathrm{MKS}$ mass flow controller. Argon is bubbled through $\mathrm{TiCl}_{4}$ and therefore becomes saturated with $\mathrm{TiCl}_{4}$ vapor. The Clausius-Clapeyron equation gives the change in vapor pressure of $\mathrm{TiCl}_{4}$ with temperature, see Figure 10 . The pressure and 


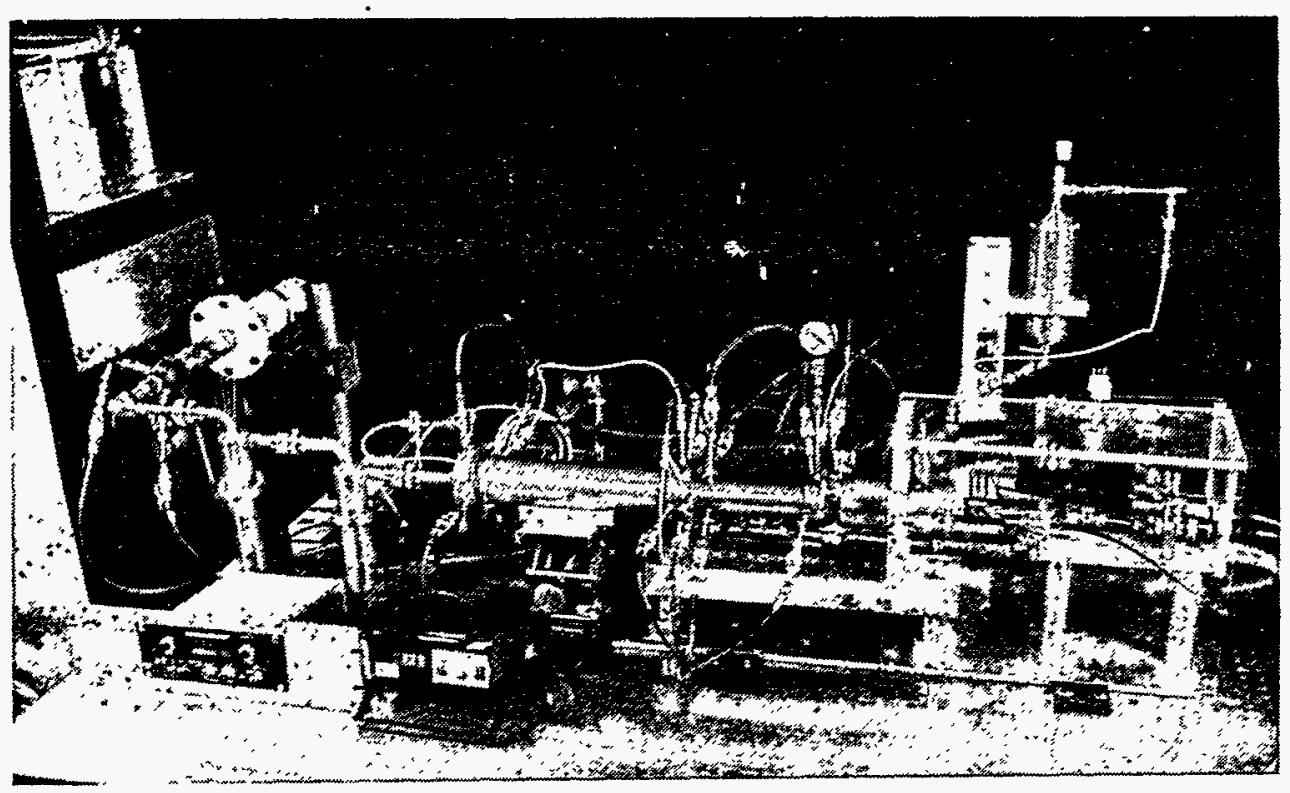

Figure 7. The lab-scale plasma quench system.

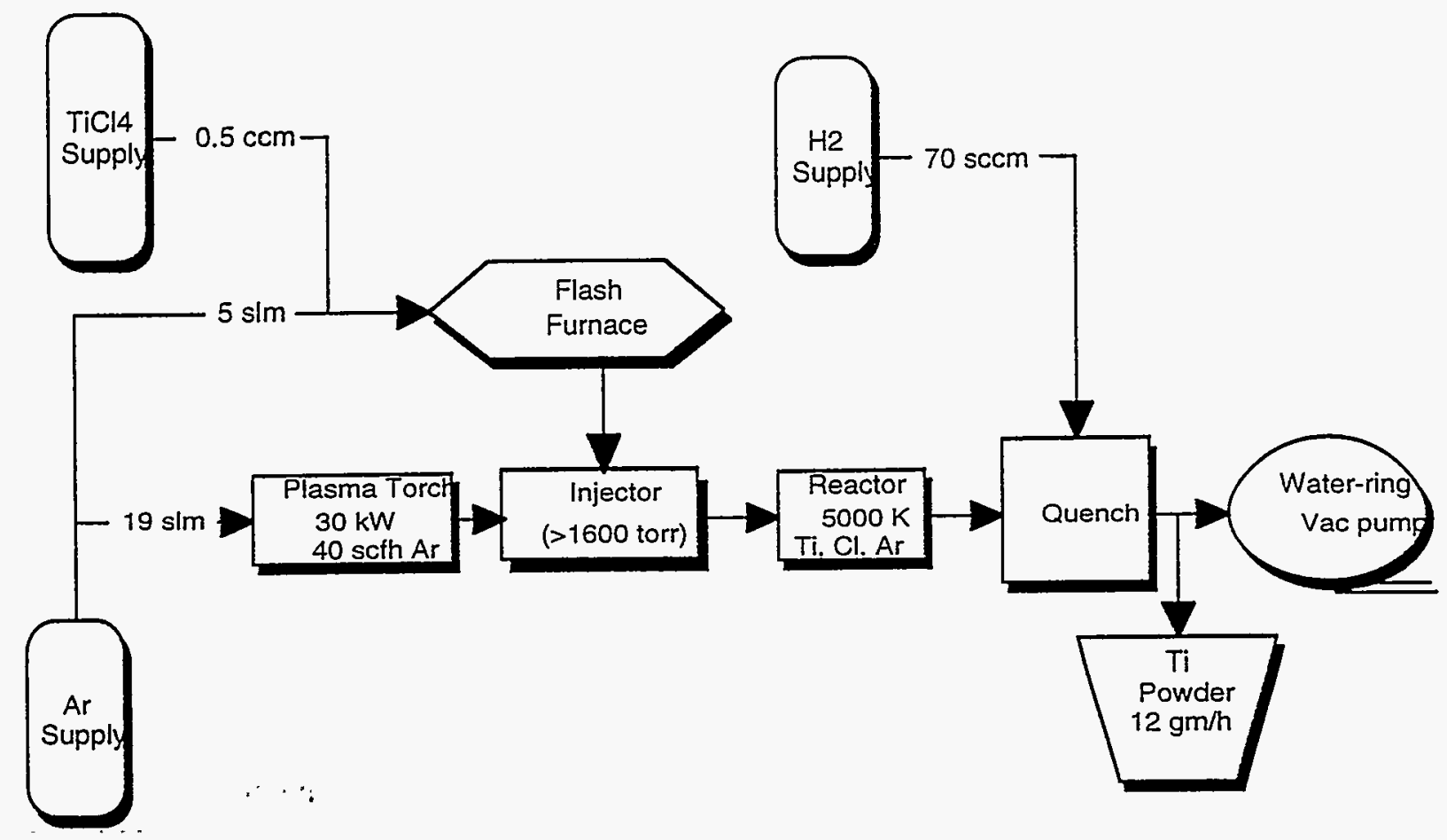

Figure 8. Diagram of the plasma quench system. 


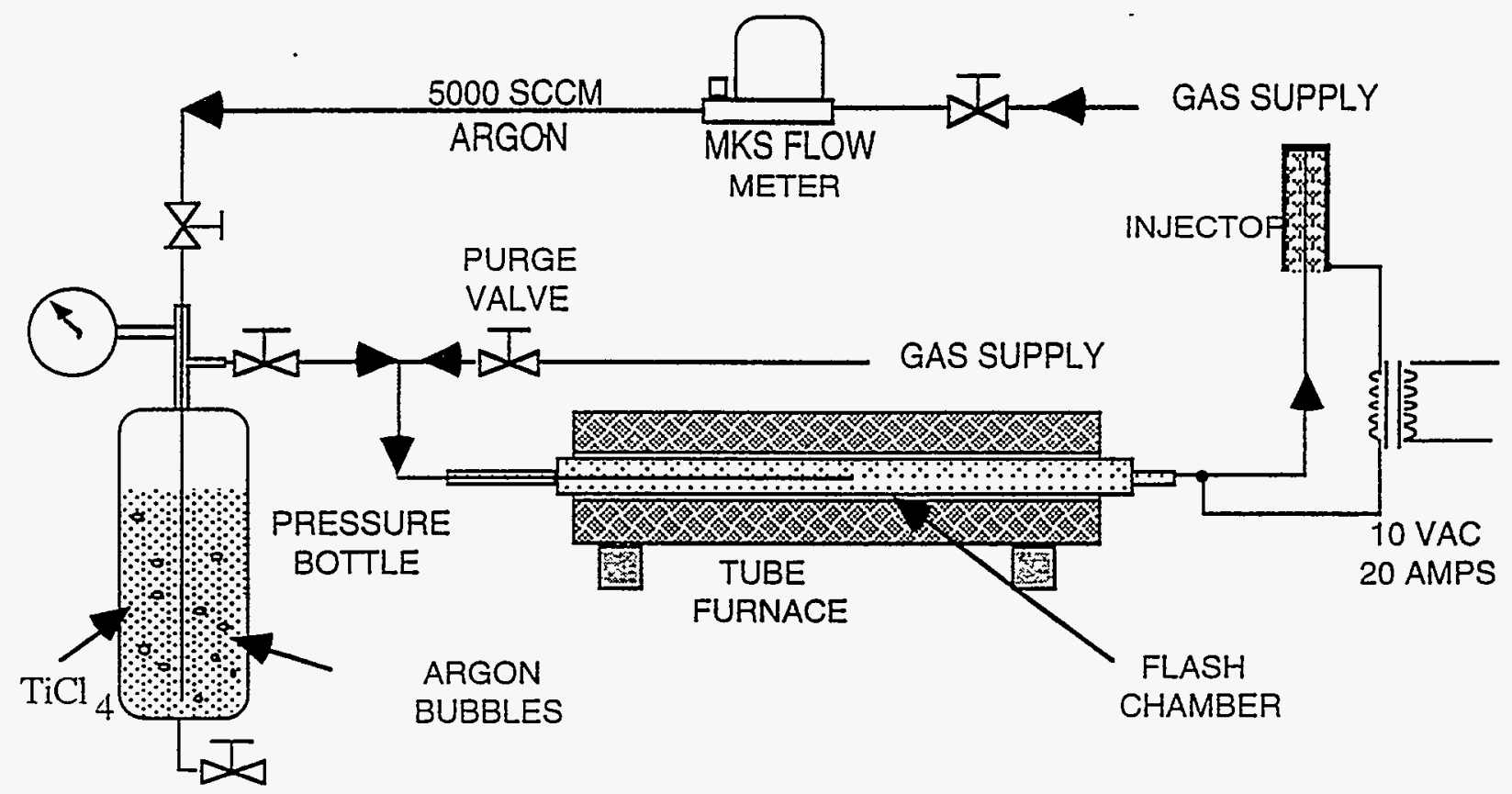

Figure 9. $\mathrm{TiCl}_{4}$ injection system used for feeding $<10 \mathrm{~g} / \mathrm{h}$.

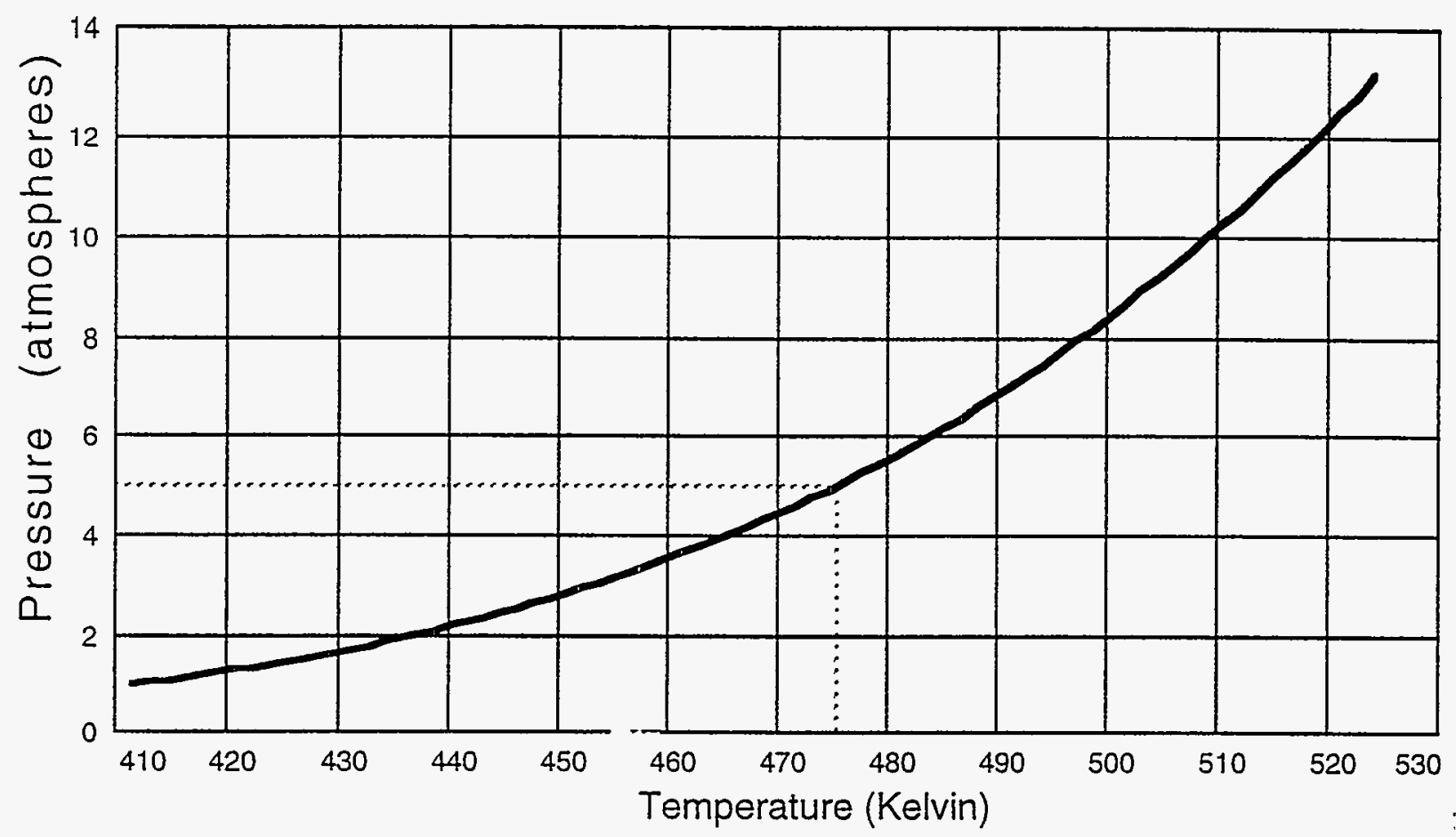

Figure 10. Vapor pressure (in atmospheres) of $\mathrm{TiCl}_{4}$ versus temperature based on the ClausiusClapeyron equation. 
temperature of the bottle controls the amount of $\mathrm{TiCl}_{4}$ carried as vapor into the reactor. $\mathrm{A}$ pressure of $500 \mathrm{kPa}$ Ar with a flow of $5 \mathrm{sLm}$ at ambient temperature produces a mass flow rate of $5 \mathrm{~g} / \mathrm{h}$ of $\mathrm{TiCl}_{4}$. The saturated vapor enters a flash chamber where the mixture is heated to approximately $250^{\circ} \mathrm{C}$ to ensure uniform mixing. The hot gas mixture leaves the flash chamber through a Joule-heated $1 / 16$ in. diameter stainless steel line. The end of the stainless steel line is welded to a nickel orifice housed in a $1 / 4$ in. diameter stainless steel housing. Alumina insulation is used to isolate the injection tube from the housing. The housing also provides a connection point for one end of the heating circuit as shown in Figure 9.

Feeding $\mathrm{TiCl}_{4}$ at rates higher than $10 \mathrm{~g} / \mathrm{h}$ requires vaporization. The diagram shown in Figure 11 illustrates how this system is configured. $\mathrm{TiCl}_{4}$ is placed in an argon-pressurized $(500 \mathrm{kPa})$ bottle from which it is injected into a heated mixing chamber. Flow out of the pressure bottle is controlled by a calibrated metering valve and measured by a variable area flowmeter at the gas inlet. At atmospheric pressure, $\mathrm{TiCl}_{4}$ boils at $138^{\circ} \mathrm{C}$, while above $500 \mathrm{kPa} \mathrm{TiCl}$ requires temperatures in excess of $200^{\circ} \mathrm{C}$ in order to vaporize. The temperature of the flash chamber is maintained at $275^{\circ} \mathrm{C}$ by a resistance-heated tube furnace. At this temperature and pressure, $\mathrm{TiCl}_{4}$ vaporizes and mixes with the argon carrier gas. The gas mixture exits the mixing chamber, through a stainless steel tube, into the injector section, identical to the system described for the lower flow rate. The stainless steel line is maintained at $250^{\circ} \mathrm{C}$ through Joule heating. A flow of $0.25 \mathrm{ccm}$ of $\mathrm{TiCl}_{4}$ and $5 \mathrm{sccm}$ of $\mathrm{Ar}$ is maintained during injection, which results in a feed rate of $26 \mathrm{~g} / \mathrm{h} \mathrm{TiCl}_{4}$.

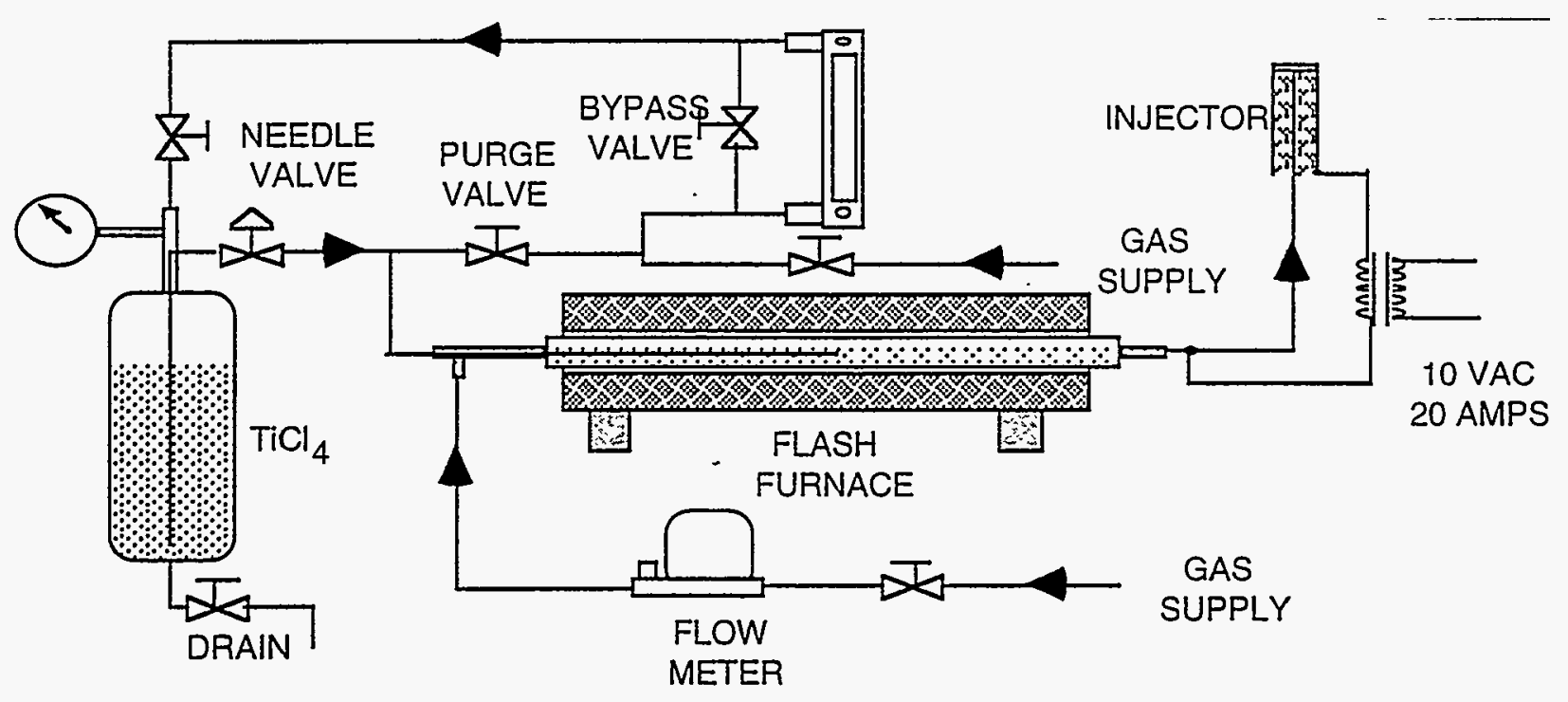

Figure 11. $\mathrm{TiCl}_{4}$ injection system used for feeding $>10 \mathrm{~g} / \mathrm{h}$. 


\section{EXPERIMENTAL PROCEDURE}

The plasma quench system consists of a $30 \mathrm{~kW}$ nontransferred arc plasma torch connected to an injector, followed by the reactor and then by the quench section. The plasma torch is connected to two $60 \mathrm{~kW}$ TAFA power supplies that are wired together in parallel. The power supplies are capable of being configured for 100, 200 and $400 \mathrm{VDC}$ open circuit voltage. Under normal operation, the power supplies are configured at $200 \mathrm{VDC}$ open circuit and operate at $30 \mathrm{VDC}$ and $1200 \mathrm{~A}$. Argon containing about $2.5 \% \mathrm{H}_{2}$ is used as the torch gas, flowing at $28 \mathrm{sLm}$. Approximately $4 \mathrm{VDC}$ is dropped across the power leads from the power supplies to the torch. The heat removed by the torch cooling water accounts for about $20 \mathrm{~kW}$, the injector cooling water removes another $6 \mathrm{~kW}$, leaving about $3 \mathrm{~kW}$ of energy in the gas.

The carrier gas containing $\mathrm{TiCl}_{4}$ vapor is introduced into the injector section as discussed above. The carrier gas and $\mathrm{TiCl}_{4}$ vapor mix with the plasma gas. This mixture of gases achieves temperatures above $5000 \mathrm{~K}$ prior to entering the nozzle. At temperatures of this magnitude the $\mathrm{TiCl}_{4}$ vapor dissociates into free species of $\mathrm{Ti}$ and $\mathrm{Cl}$. At the nozzle, the gas rapidly expands, converting heat to kinetic energy and dropping the temperature of the gas rapidly enough to prevent back reaction of the $\mathrm{Cl}$ with the Ti. The Ti condenses in the nozzle to form $10 \mathrm{~nm}$ nanocrystalline particles. These particles agglomerate into clusters $\sim 100 \mathrm{~nm}$ in diameter. Al this point, $\mathrm{H}_{2}$ is injected into the supersonic gas stream to stabilize the products and remove the kinetic energy of the gas-powder stream to prevent reheating of the powders. The gas exits the quench section at about $350^{\circ} \mathrm{C}$ and enters the first of two cyclone separators where the Ti powder is collected in Pyrex-glass sample tubes. The acid $(\mathrm{HCl})$, excess $\mathrm{H}_{2}, \mathrm{Ar}$, and uncollected powder then enter a water-ring vacuum pump. At the pump exit, $\mathrm{H}_{2}$ and $\mathrm{Ar}$ are flared by an $\mathrm{N}_{2}$ eductor while the $\mathrm{HCl}$ reacts with $\mathrm{NaOH}$ that is injected into the water-seal vacuum pump liquor.

Nanocrystalline Ti powder is extremely pyrophoric. In order to analysis the powder, it has to be semiconsolidated under inert conditions to prevent reaction with air. A method was developed to extract the powders from the system and perform a cold consolidation without installing elaborate valves and seals. After the system is run and the torch turned off, an Ar purge is maintained to prevent air contamination of the powder. A positive pressure of a few $\mathrm{kPa}$ above atmospheric pressure is maintained in the system. The collection tubes are connected to the system through Kwik-Flange connectors. An $\mathrm{Al}$ plug is used to quickly seal each of the collection tubes as the Kwik-Flange is opened. After sealing the collection tubes, they are transferred to an Ar-filled glove box where a small sample of powder is extracted and placed into a compaction die. The die is sealed in a zip-lock bag prior to transferring it from the glove box. The $1.27 \mathrm{~cm}$ diameter die is placed in a press and cold compacted with a pressure of $3.45 \mathrm{MPa}$ while still in the zip-lock bag. The samr'o is then removed from the bag and die and analyzed by XRD. 


\section{ENERGY BALANCE}

To determine the amount of energy available for dissociation of the $\mathrm{TiCl}_{4}$, an accurate energy balance must be performed. The thermal energy induced into the gas leaving the plasma torch is equal to the electrical input energy, as shown by the $\mathrm{kW}$ Torch curve in Figure 12, minus the torch cooling water losses (Torch Loss curve). The sum of all the thermal losses (Total Loss curve) should be equal to the input power ( $\mathrm{kW}$ Torch curve).

The energy in the gas exiting the plasma torch amounts to about $3 \mathrm{~kW}$ or $10,800 \mathrm{~kJ} / \mathrm{h}$. The temperature of Ar flowing at $27 \mathrm{sLm}$ containing $10,800 \mathrm{~kJ}$ or $149 \mathrm{~kJ} / \mathrm{mole}$ is calculated to be $7174 \mathrm{~K}$. Another $\mathrm{kW}$ is removed from the gas prior to reaching the nozzle, reducing the gas temperature to $4780 \mathrm{~K}$. At this temperature the $\mathrm{TiCl}_{4}$ will still dissociate before it enters the nozzle. Since the nozzle section has only one cooling circuit, it is difficult to separate the losses before and after the nozzle. Figure 12 shows that the total nozzle losses are about 2 to $2.5 \mathrm{~kW}$. The cooling water in the quench section removes another $\mathrm{kW}$ from the gas stream. Hydrogen gas at ambient temperature is added to the flow in the quench section at the exit of the nozzle to aid in cooling and stabilizing the products. A small amount of energy is retained in the gas flow as it exits the system (Exit Gas Energy curve).

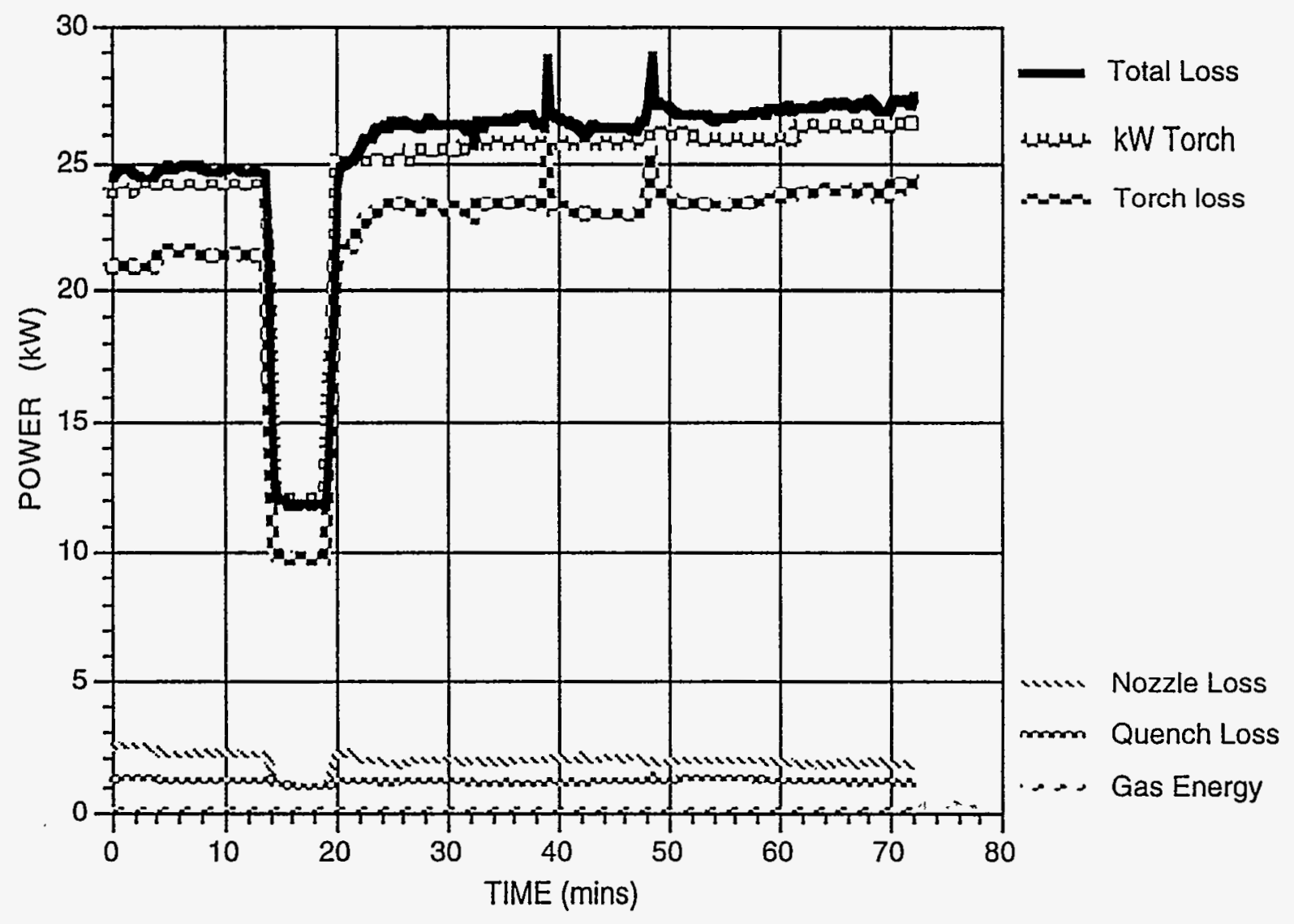

Figure 12. Energy balance for $\mathrm{TiCl}_{4}$ reduction; $27 \mathrm{sLm}$ Ar plus $2.5 \% \mathrm{H}_{2}$ torch gas, $5 \mathrm{~g} / \mathrm{h} \mathrm{TiCl} 4$, 5 sccm Ar carrier gas. 


\section{ENTHALPY PROBE DIAGNOSTICS}

It was determined early that diagnostics and modeling would play an important role in the successful completion of this project. Measurements of the enthalpy in the reaction section of the system were performed with two reasons in mind. First, the sensitivity of the system to temperature, pressure, and flow required accurate measurements of these states for the setting of process conditions and design parameters. Second was the concern about the possibility of mixing the reactants within the highly viscous plasma. Both system sensitivities and mixing pertain to obtaining a high conversion of $\mathrm{TiCl}_{4}$ to $\mathrm{Ti}$. The enthalpy probe used in this experiment, similar to that shown in Figure 13, is described in detail by Swank, et al. ${ }^{19}$

\section{Temperature Distributions}

Initially, high concentrations of $\mathrm{H}_{2}$ were used in the plasma gas. Doing this had two effects on the performance of the system. First, the torch suffered from severe erosion of the copper anode during operation with more than $10 \% \mathrm{H}_{2}$. Second, and most important, the temperatures required for the reaction to occur were not being obtained. The original concept employed a $16 \mathrm{~cm}$ long reactor for mixing prior to entering the nozzle. Enthalpy probe measurements were taken axially and radially in this reactor section. The temperature distributions measured by the enthalpy probe for the $16 \mathrm{~mm}$ diameter reactor, with the torch operating on a gas mixture of $64 \% \mathrm{H}_{2}$ with Ar (total flow-115 scfh) at $110 \mathrm{VDC}$ and $200 \mathrm{~A}$, are shown in Figures 14 (axial) and 15 (radial). The beginning of the reactor section was located approximately $10 \mathrm{~cm}$ from the torch exit. The temperature in the gas stream dropped from $-2200 \mathrm{~K}$ at $16 \mathrm{~cm}$ to $1200 \mathrm{~K}$ at the exit. The radial temperature distribution is relatively flat in both positions measured, with a steep gradient near the wall.

It was obvious from these results that the reactor was both too long and too remote from the torch for effective heat retention by the reactants. The diameter of the test reactor was questionable since it was $6 \mathrm{~mm}$ larger than the injection section and, therefore, caused gas expansion and recirculation from the $10 \mathrm{~mm}$ diameter injector section that was between the reactor and the torch. Following this test, the system was modified by shortening the test section and using the same diameter as in the actual reactor and injector sections. The axial measurements were repeated using this shorter section; the measurements included most of the injector section. Figure 16 shows the relative positions of the two different sets of measurements and Figure 17 gives the resulting temperature profile.

Temperatures range from $2700 \mathrm{~K}$ at the injector inlet to $1800 \mathrm{~K}$ at the reactor exit for operating conditions of $77 \% \mathrm{H}_{2}$ with $\mathrm{Ar}$ (total flow-175 scfh) with a torch voltage of $132 \mathrm{VDC}$ and current of $250 \mathrm{~A}$. It became apparent that the required temperature could not be reached with a high $\mathrm{H}_{2}$ plasma gas in the torch configuration that was being used.

\section{Product Mixing}

In the same experimental setup, krypton gas was injected into the plasma to simulate $\mathrm{UF}_{6}$. Although $\mathrm{Kr}$ gas is monatomic and will behave differently from a more complex gas such as $\mathrm{TiCl}_{4}$ or $\mathrm{UF}_{6}$, it was the most dense gas that could be introduced into the system and be detected (gas analyzer limited to $<100 \mathrm{amu}$ ). The presence of $\mathrm{Kr}$ gas was immediately detected at high concentrations in the center of the plasma as shown in Figure 18. The concentration of $\mathrm{Kr}$ gas 


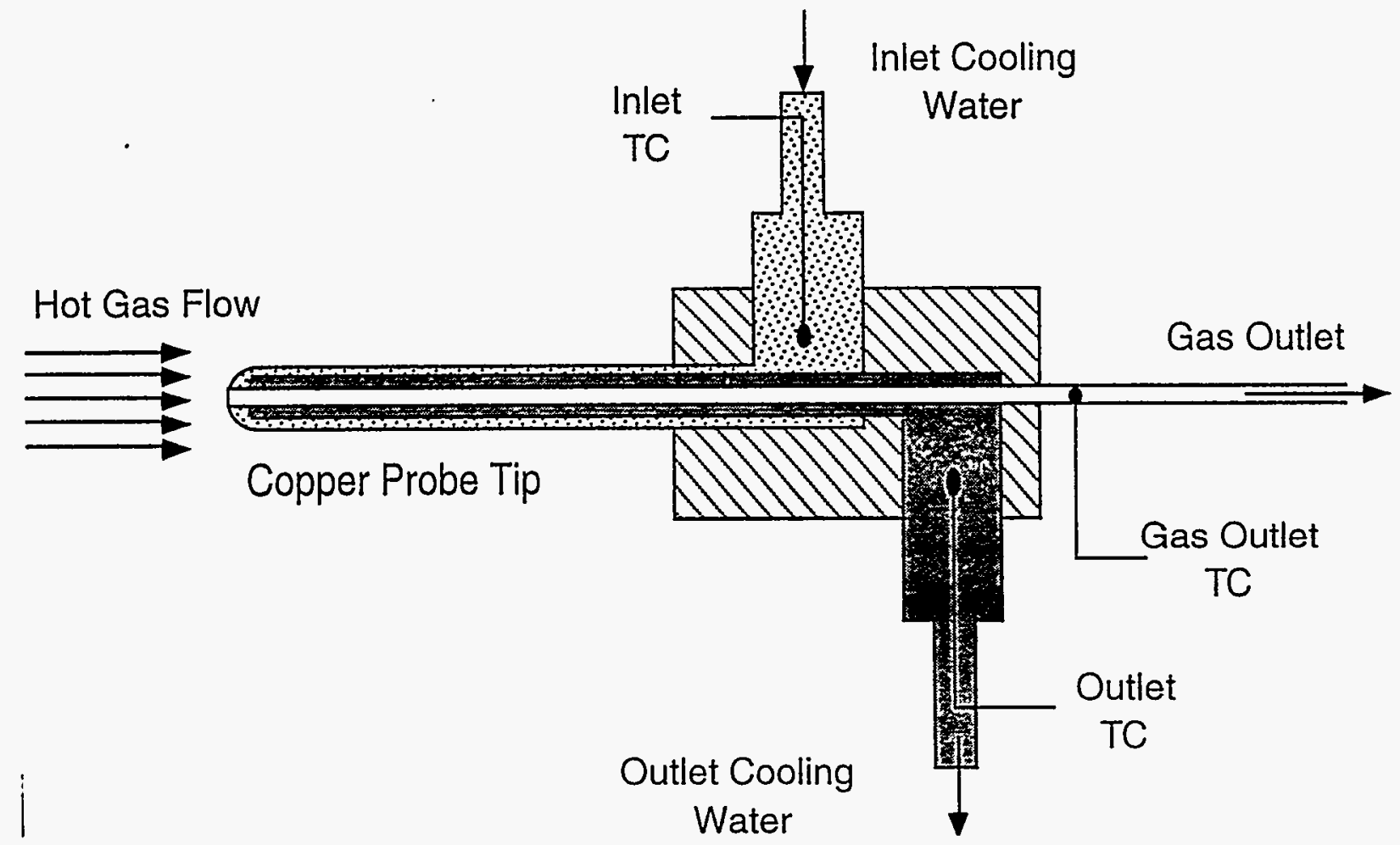

Figure 13. Diagram of the enthalpy probe used to determine temperature distributions in the plasma quench reactor.

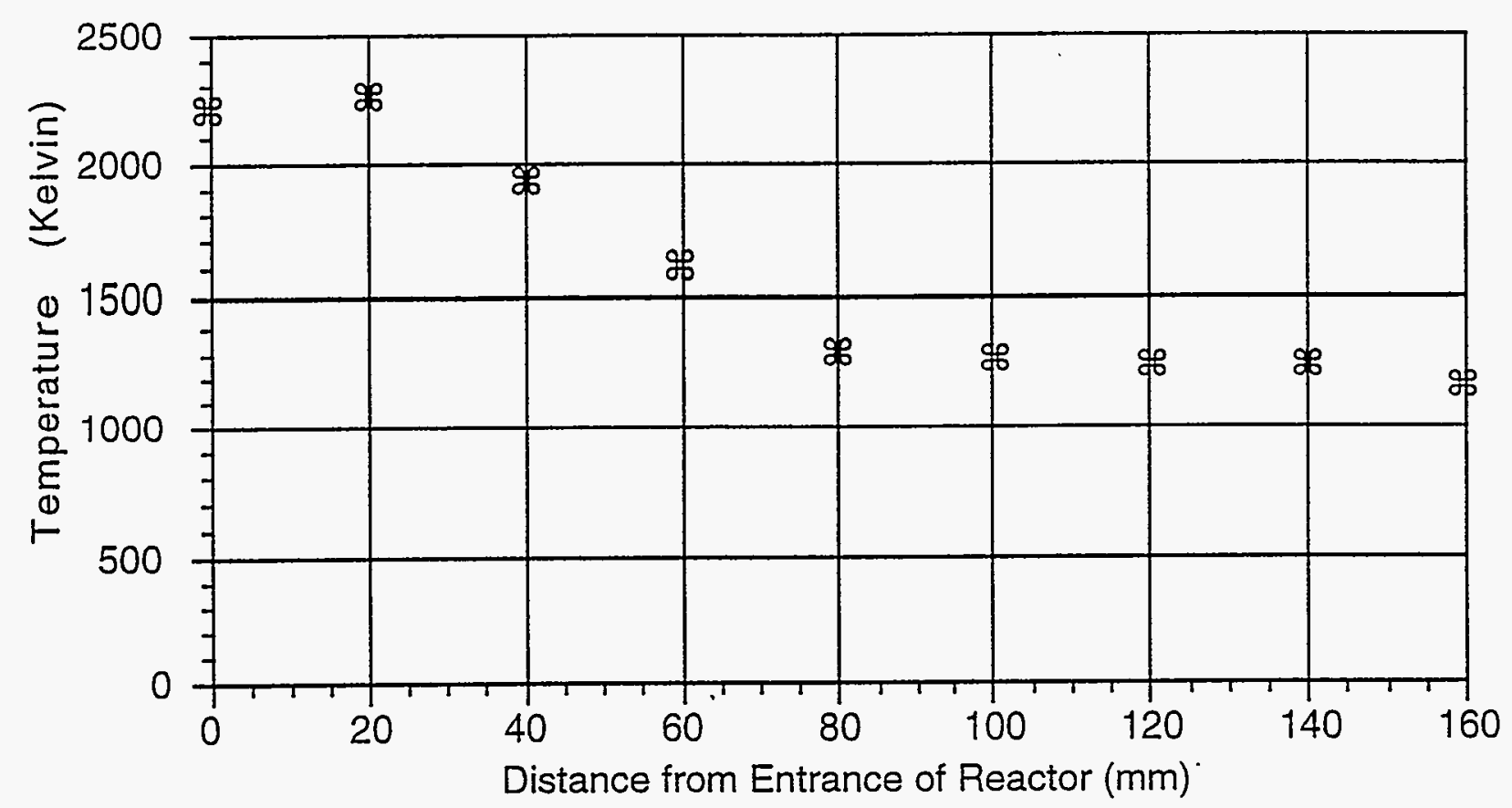

Figure 14. Axial temperature distribution in the $16 \mathrm{~mm}$ diameter reactor section operating on $64 \% \mathrm{H}_{2}$ with $\mathrm{Ar}$ at $110 \mathrm{VDC}$ and $200 \mathrm{~A}$. 


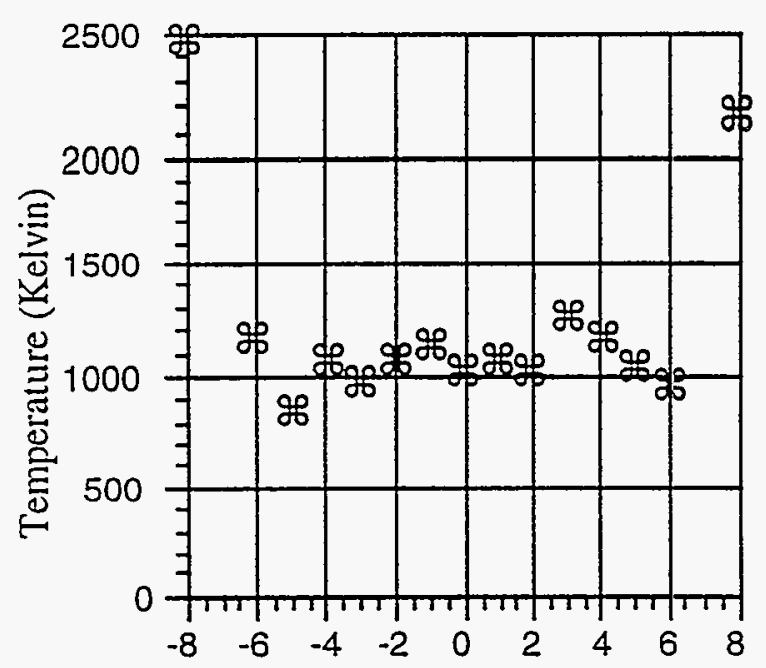

(a) Axial Position (mm) at Exit

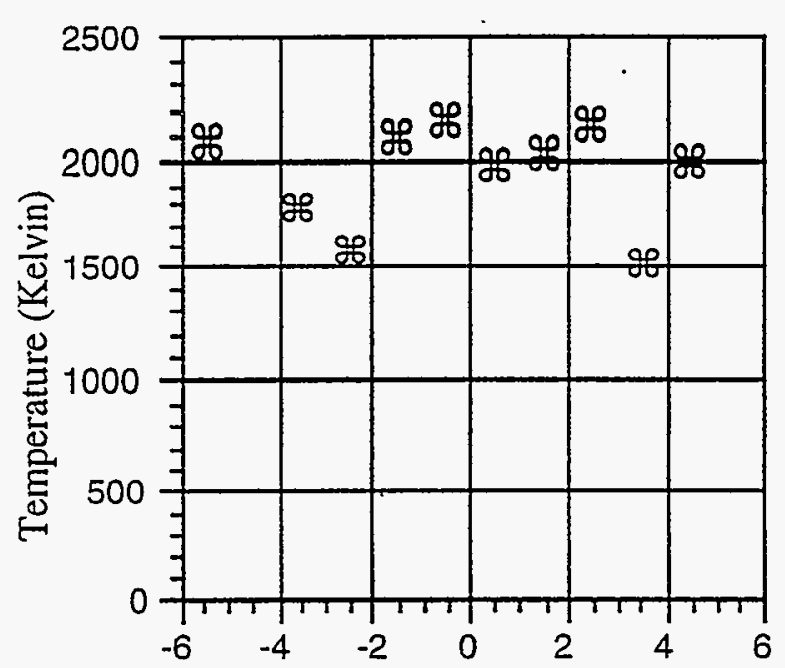

(b) Axial Position (mm) at Entrance

Figure 15. Radial temperature distribution in the $16 \mathrm{~mm}$ diameter reactor section operating on $64 \% \mathrm{H}_{2}$ with $\mathrm{Ar}$ at $110 \mathrm{VDC}$ and $200 \mathrm{~A}$ at (a) $160 \mathrm{~mm}$ and (b) $8 \mathrm{~mm}$.
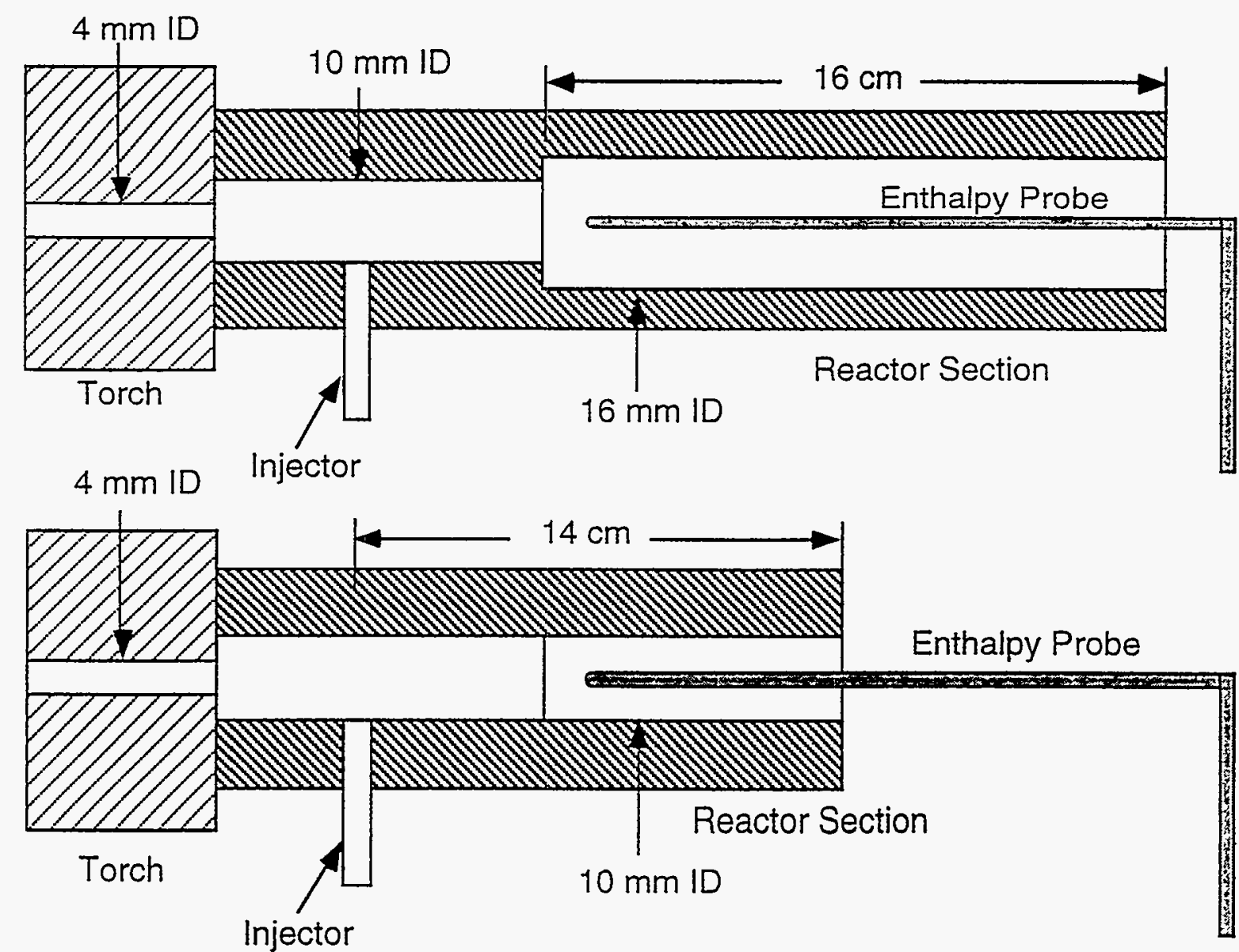

Figure 16. Diagram of the two test configurations used during the enthalpy probe work. 


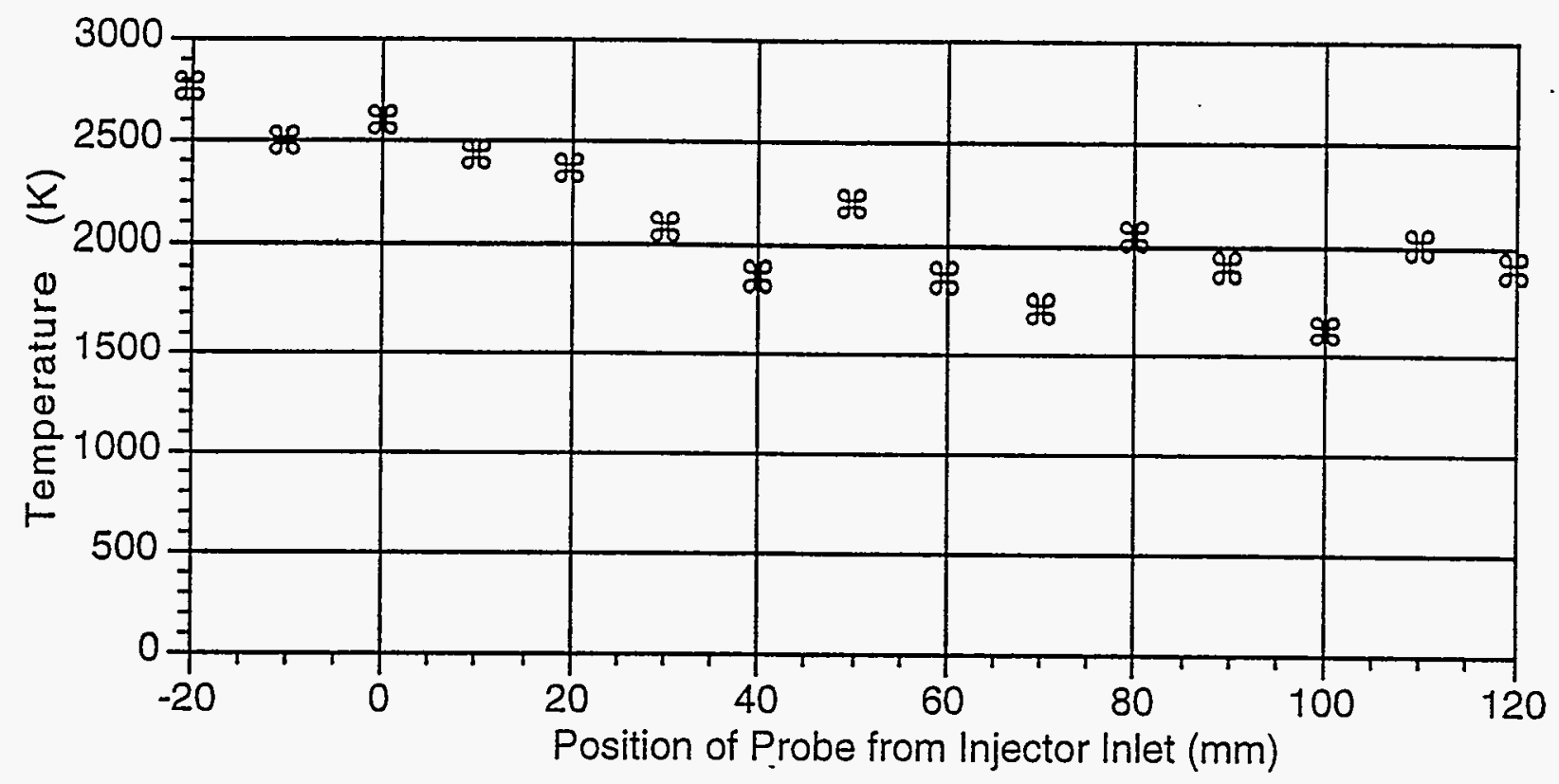

Figure 17. Temperature distribution in the injector and reactor test sections at operating conditions of $77 \% \mathrm{H}_{2}$ with $\mathrm{Ar}$ (total flow-175 scfh) with a torch voltage of $132 \mathrm{VDC}$ and current of $250 \mathrm{~A}$.

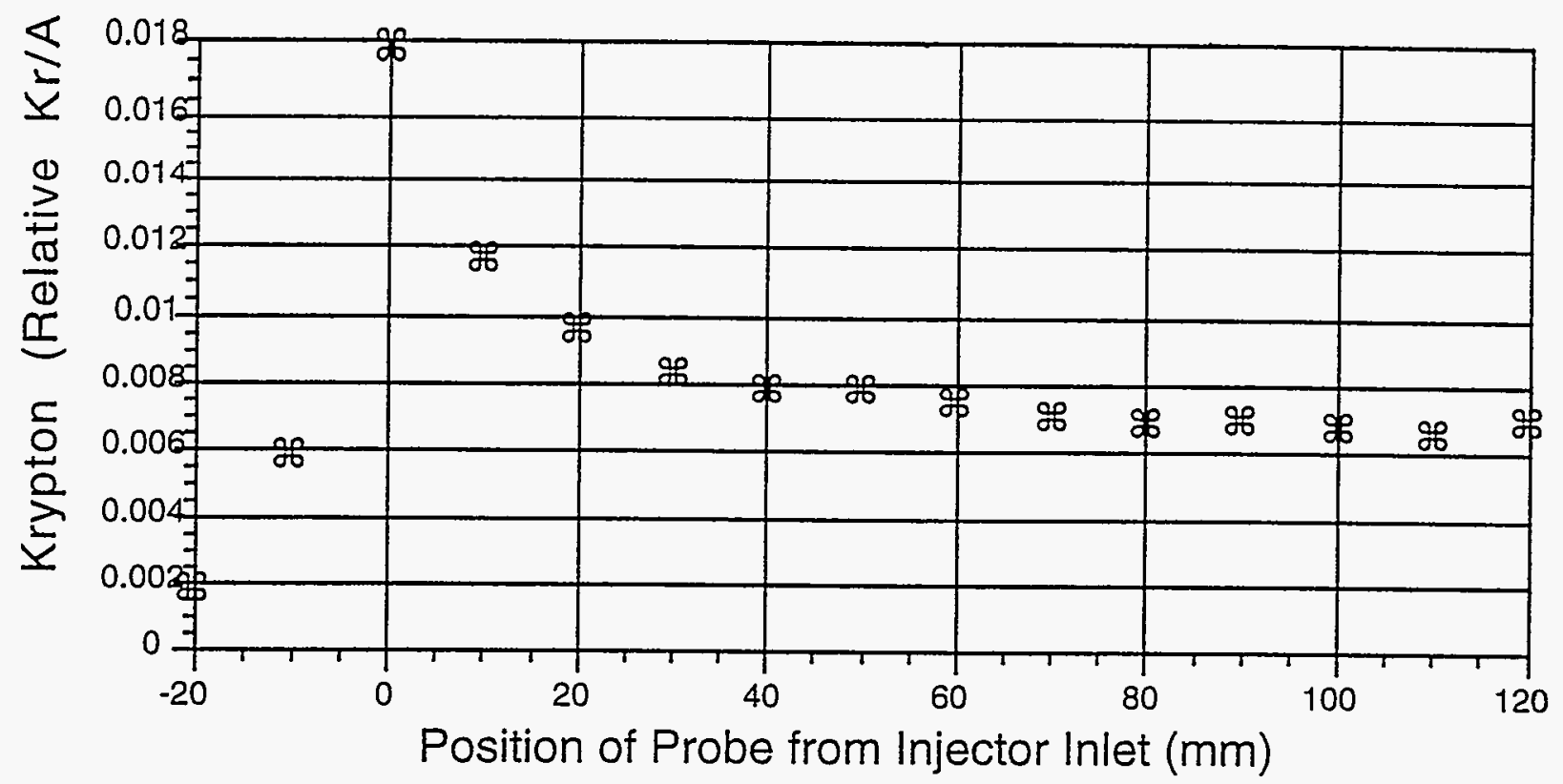

Figure 18. Krypton gas distribution in the injector and reactor section of the plasma quench system. 
then decreases at the plasma center, indicating a uniform mixing distribution. This finding is significant in that the $\mathrm{TiCl}_{4}$ gas should behave in a similar manner, providing a uniform distribution of $\mathrm{TiCl}_{4}$ in the plasma, which would provide for uniform heating prior to the quench nozzle. 


\section{RESULTS AND DISCUSSION}

Throughputs ( $<5 \mathrm{~g} / \mathrm{h}$ ) of $99 \%$ pure Ti metal have been produced by this process using very dilute reactants in an Ar plasma. The most recent objective has been to scale up the $\mathrm{Ti}$ production to $50 \mathrm{~g} / \mathrm{h}$. Several engineering problems were encountered, including reactor and injector design, maintaining the enthalpy for the reaction, product contamination, arc containment, high velocity injection of $\mathrm{TiCl}_{4}$, quench conditions, exhaust gas acid control, and powder handling. Product quality remains the most important question. Scale up experiments to date have produced $\mathrm{Ti}$ powders at the rate of $25 \mathrm{~g} / \mathrm{h}$ with as little as $2 \%$ chloride present in the product. This impurity content is not much different from the chloride content of $\mathrm{Mg}$ - or Na-reduced Ti sponge. Analyzing the powders has been difficult because of the pyrophoric nature of submicron $\mathrm{Ti}$.

The major subchloride contamination found in the $\mathrm{Ti}$ product has been identified as $\mathrm{TiCl}$, which is unstable at low temperatures. Hydrogen infusion while heating the powders to $400^{\circ} \mathrm{C}$ removes most of these residual chlorides. ${ }^{d}$ The Ti product collected in quartz tubes is black and flocculent. When the powder is exposed to air, it burns with a strong chlorine odor and, in most cases, forms a yellow powder indicating formation of TiO. It is not clear whether all the TiO formed is from the decomposition of $\mathrm{TiCl}$ or if some is from the oxidation of Ti. SEM micrographs of this gray powder, produced during recent experiments, are shown in Figure 19.

The important feature of the product is its uniform nanosize. As shown above, the powder material is agglomerated into 100 to $200 \mathrm{~nm}$ clusters. Each cluster is made up of a number of 30 to $50 \mathrm{~nm}$ particles. It is assumed that the nanosized particles are formed from homogeneous nucleation during the quenching stage, which would account for their uniform size.

The latest work performed was to produce Ti using a very dilute flow $(<5 \mathrm{~g} / \mathrm{h})$ in an $\mathrm{Ar}$ plasma with $2.5 \% \mathrm{H}_{2}$. Several grams of black powder from these runs were compacted into pellets as described in the experimental procedure section. X-ray diffraction (XRD) results (Figure 20) indicated a significant peak of Ti, along with some peaks of TiN (Osbornite) and TiO. The presence of TiN indicates some air infiltration during the process.

During examination of the setup, an air leak was found in the plasma torch. The dilute flow experiment was performed again after replacing seals in the torch. Figure 21 shows the XRD results obtained from a compacted pellet from the subsequent run. No TiN was observed, indicating that the leak was fixed. The major peaks were found to be forms of $\mathrm{TiO}$ and $\mathrm{Ti}$. This type of result indicates that conversion of $\mathrm{TiCl}_{4}$ to $\mathrm{Ti}$ was very high, but oxygen pickup in the nanosize powder is difficult to control. Handling of these powders remains a major challenge in developing this process.

d. Private conversation with Prof. R. Kearney, University of Idaho, February 1994. 

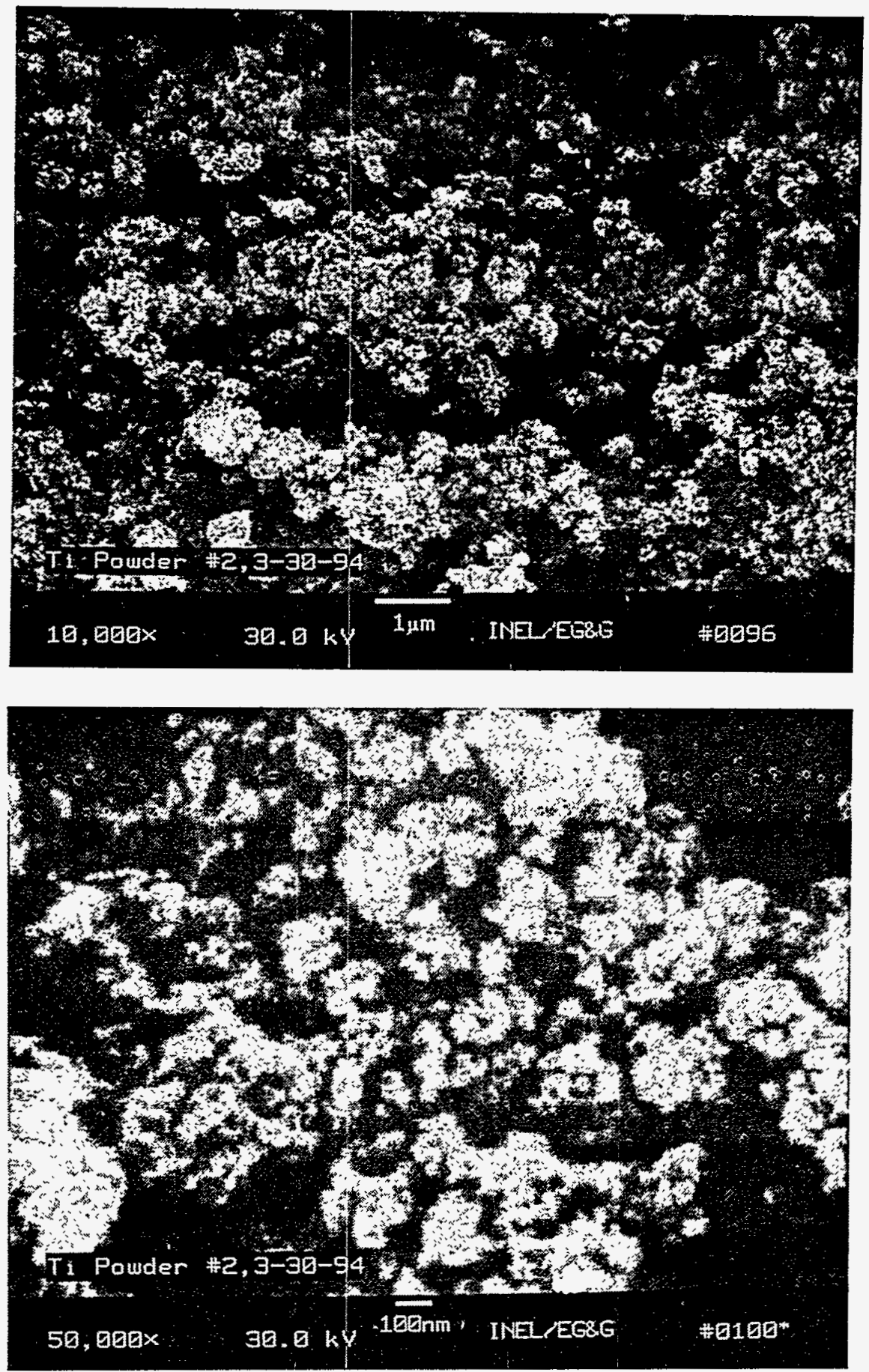

Figure 19. SEM micrographs of Ti powder produced by plasma quenching (after exposure to air). (a) $10,000 x$ and (b) $50,000 x$. 


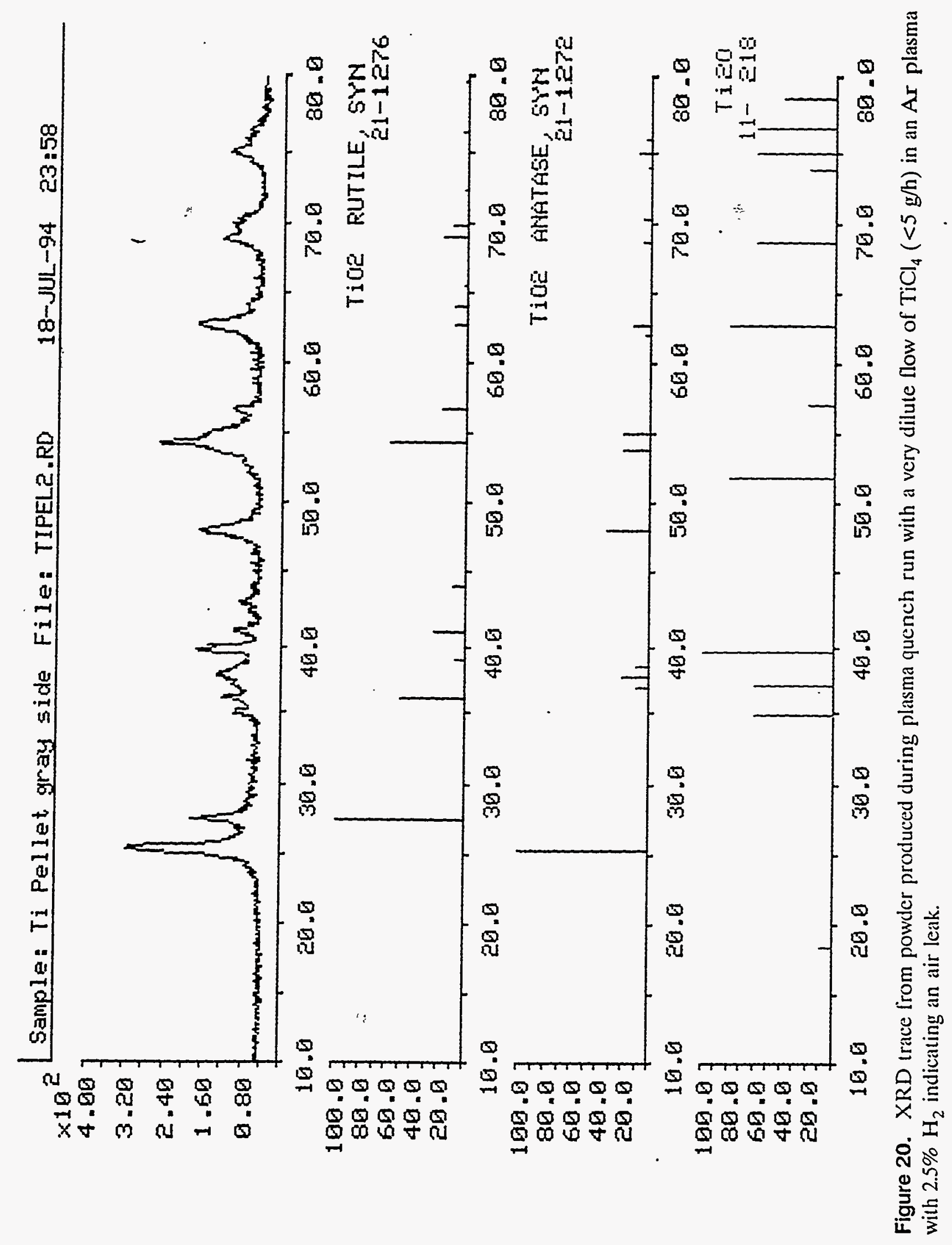




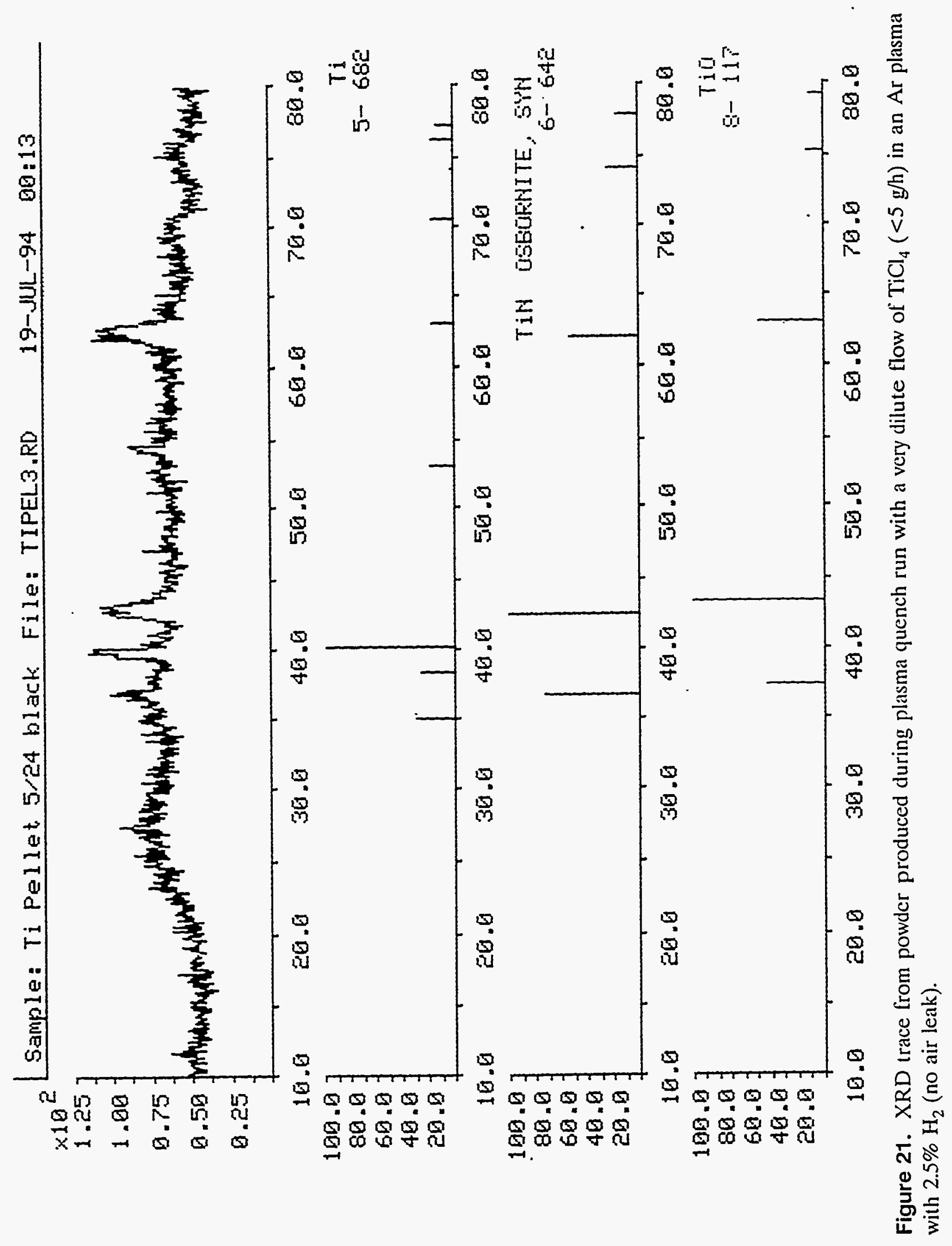




\section{SUMMARY}

A new system for injecting $\mathrm{TiCl}_{4}$ into the plasma quench reactor was developed. Prior to this development, injector plugging was a major impediment in the process. The new injection system consists of a stainless steel bottle where the $\mathrm{TiCl}_{4}$ is pressurized under argon and a meter long, $19 \mathrm{~mm}$ OD flash chamber that is heated to $250^{\circ} \mathrm{C}$ in a tube furnace. The tlow of liquid $\mathrm{TiCl}_{4}$ out of the stainless steel bottle is measured by the amount of $\mathrm{Ar}$ entering the bottle. A variable area flow meter is used to measure the argon flow. Cold $\mathrm{TiCl}_{4}$ is injected into the middle of the flash chamber where it vaporizes and mixes with Ar carrier gas. Through the use of the flash chamber, process surging and particle entrainment in the injection nozzle have been eliminated.

There has been high chloride content (subchlorides) in the product (black and highly pyrophoric) from all of the runs this year. Part of the problem was identified as an insufficient pressure drop across the quench nozzle resulting in an inadequate quench and back reactions. Also, it was determined through enthalpy probe measurements (work for the Department of Energy's $U_{6}$ project) that the temperature in the reactor was much too low to prevent back reactions prior to the quench nozzle. The temperatures measured at the exit of the reactor section were on the order of $2000^{\circ} \mathrm{C}$ instead of the $3500^{\circ} \mathrm{C}$ required.

The low pressure drop was attributed to blockage of the $\mathrm{Ca}(\mathrm{OH})_{2}$ scrubber section and a plugged HEPA filter; both were in front of the mechanical vacuum pump. The $\mathrm{Ca}(\mathrm{OH})_{2}$ scrubber section, HEPA filter, and mechanical vacuum pump were removed and a water-ring vacuum pump was installed in their place. The seal liquid in the water-ring vacuum pump is water with $\mathrm{NaOH}$ injection to control the $\mathrm{pH}$. The water-ring pump is capable of maintaining 80 torr under full load from the system.

Inadequate pressure drop across the nozzle was identified as one of the problems with the system. Information received from the University of Idaho indicated that the pressure ratio needs to be greater than 20:1 in order to prevent back reactions. The quench nozzle diameter was reduced to $2.5 \mathrm{~mm}$, from $3.5 \mathrm{~mm}$, to allow the torch to operate at higher pressures $(200 \mathrm{kPa})$ with the same gas flow.

The plasma torch has been difficult to operate on high levels of $\mathrm{H}_{2}$ due to arc attachment outside the torch causing failure of the water-cooled injector. At the time of this report, the system is being operated at a $2.5 \% \mathrm{H}_{2}$ mixture with argon. The insolator section that was used to prevent arc attachment to the injector has been removed. The injector is fixed directly to the torch. The reactor scction has been shortened to address the low temperatures at the exit.

A mixing experiment was performed, as part of another project, in which krypton gas was injected into the hot plasma gas. Distributions of the gas compositions in the plasma were measured with a gas analyzer connected to the enthalpy probe. Results indicate that the krypton is initially concentrated in the center of the plasma and then slowly equilibrates outward. $\mathrm{TiCl}_{4}$ should behave similarly, therefore mixing does not appear to be a problem. This was somewhat confirmed by the modeling work. 
A method was devised to consolidate the powder produced by plasma quenching without exposing it to air. The collection vial is carefully removed from the cyclone separator and then quickly capped. Argon is present in the vial; therefore, if the vial is not disturbed while the cap is off, little air can enter. The vial is transferred to a glove box where a powder sample is placed in a $12 \mathrm{~mm}$ OD compaction die. The die is filled and the compaction ram is set in place. The die assembly containing the powder is placed in a plastic bag and sealed. The die assembly is then transferred out of the glove box. The powder is cold compacted at a pressure of $34.5 \mathrm{MPa}$, producing a $12 \mathrm{~mm}$ OD by $3 \mathrm{~mm}$ thick specimen suitable for subsequent examination without rapid degradation of the sample.

Thermodynamic calculations show that when $\mathrm{H}_{2}$ is added to the plasma gas the temperatures required for the complete dissociation of $\mathrm{TiCl}_{4}$ cannot be reached. Because of this, $\mathrm{H}_{2}$ has been reduced to $2.5 \%$ in the plasma gas and been replaced by argon in the carrier gas. Additional calculations are being performed to assess the feasibility of using helium. 


\section{REFERENCES}

1. Yu. N. Tumanov and N. P. Galkin, Atomnaya Energiya, 37, 1974, p. 340.

2. A. L. Hare, "Nonferrous Metals and Miscellaneous Applications of Plasma Technology," Plasma Technology in Metallurgical Processing, J. Feinman, Ed., Iron and Steel Society, Inc., 1987, p. 175.

3. J. S. Featers and J. J. Moore, "Applications of Nonequilibrium Gas Dynamics Techniques to the Plasma Synthesis of Ceramic Powders," Z. A. Munir and J. B. Holts, eds., New York: VCH, 1990 , p. 431-446.

4. R. L Stephens, et al., "A Thermodynamic Analysis of the Synthesis of Titanium Carbide in a Thermal Plasma Reactor," Journal of Material Synthesis and Processing, 1, 2, 1993.

5. E. Neuenschwander, "Herstellung Und Charakterisierung Von Ultrafeinen Karbiden, Nitriden Und Metallen," Journal of Less Common Metals, II, 1966, pp. 365-375.

6. P. H. Dundas and M. L. Trope, "Titanium Dioxide Production by Plasma Processing," CEP, 66, 1970, pp. 66-71.

7. A. L. Hare, "Large Thermal Plasma Devices-Some Aspects of Their Design and Operation," Fifth International Symposium on Plasma Chemistry, (IUPAC), Edinburgh, Scotland, 1981.

8. L. Kerker and R. Muller, "The Plasma Reforming Process from Chemische Werke Hüls AG for the Production of Reducing Gases," Stah und Eisen, 1984.

9. T. Ikeshima, "Recent Developments in Titanium Sponge Production," Titanium Science and Technology, Proceeding of the Fifth International Conference on Titanium, Munich, FGR, September 1984.

10. K. A. Bunting, "Sodium and Titanium Tetrachloride Feed Systems for a Plasma Route to Titanium," Sixth International Symposium on Plasma Chemistry, Montreal, Quebec, Canada, July 1983, 1, pp. 193-196.

11. W. H. Gauvin and H. K. Choi, "Plasmas in Extractive Metallurgy," Plasma Processing and Synthesis of Materials, Materials Research Society Symposia, Boston, MA, November 1983, pp. 77-89.

12. P. Tsantrizos and W. H. Gauvin, "Characteristics of Transferred-Arc Plasmas at High $\mathrm{TiCl}_{4}$ Concentration," Plasma Chemistry and Plasma Processing, 10, 1, 1990, pp. 99-113.

13. W. H. Gauvin, M. G. Drouet, and R. J. Munz, "Developments in Plasma Processes for Extractive Metallurgy," Journal of Metals, 39, 12, 1987, pp. 14-17. 
14. J. A. Bester, J. A. De Beer, and A. W. Griffin, "Thermal Plasma Reduction of $\mathrm{UF}_{6}$ to $\mathrm{UF}_{4}$ with Hydrogen-Laboratory to Pilot Plant," Proceedings of the International Symposium on Plasma Chemistry, (ISPC-11), August 1993.

15. J. W. Sears, "Rapid Solidification Processing of High Temperature and Reactive Alloys," Ph.D. Thesis, 1988.

16. S. V. Joshi, et al., Plasma Chemistry and Plasma Processing, 10, 2, 1990, p. 339.

17. OUTOKUMPU HSC Chemistry Ver. 1.12, Chemical Reaction and Equilibrium Software with Extensive Thermochemical Database, ARSoftware.

18. G. J. VanWylen and R. E. Sonntag, eds., Fundamentals of Classical Thermodynamics, SI Version $2^{e}$, 2nd edition, John Wiley \& Sons, 1978, p. 603.

19. W. D. Swank, J. R. Fincke, and D. C. Haggard, "Modular Enthalpy Probe and Gas Analyzer for Thermal Plasma Measurements," Rev. Sci. Instrum., 64, 1, January 1993, American Institute of Physics, p. 56-62. 